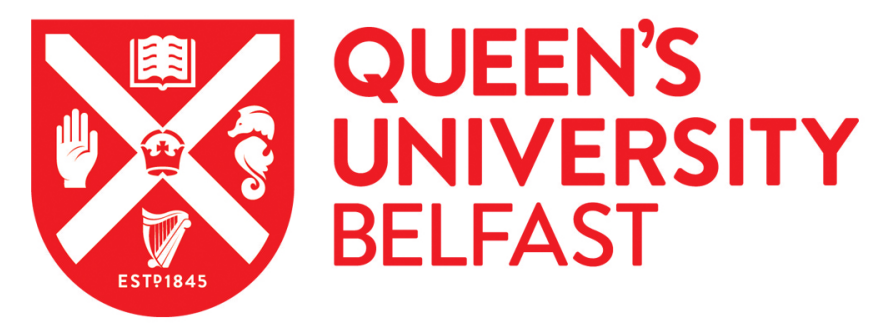

\title{
Regional climate changes drive increased scaled-chrysophyte abundance in lakes downwind of Athabasca Oil Sands nitrogen emissions
}

Mushet, G. R., Laird, K. R., Das, B., Hesjedal, B., Leavitt, P. R., Scott, K. A., Simpson, G. L., Wissel, B., Wolfe, J. D., \& Cumming, B. F. (2017). Regional climate changes drive increased scaled-chrysophyte abundance in lakes downwind of Athabasca Oil Sands nitrogen emissions. Journal of Paleolimnology, 58(3), 419-435. https://doi.org/10.1007/s10933-017-9987-6

\section{Published in:}

Journal of Paleolimnology

\section{Document Version:}

Peer reviewed version

Queen's University Belfast - Research Portal:

Link to publication record in Queen's University Belfast Research Portal

\section{Publisher rights}

(C) 2017 Springer Science+Business Media B. V.

This work is made available online in accordance with the publisher's policies. Please refer to any applicable terms of use of the publisher.

\section{General rights}

Copyright for the publications made accessible via the Queen's University Belfast Research Portal is retained by the author(s) and / or other copyright owners and it is a condition of accessing these publications that users recognise and abide by the legal requirements associated with these rights.

\section{Take down policy}

The Research Portal is Queen's institutional repository that provides access to Queen's research output. Every effort has been made to ensure that content in the Research Portal does not infringe any person's rights, or applicable UK laws. If you discover content in the

Research Portal that you believe breaches copyright or violates any law, please contact openaccess@qub.ac.uk. 


\section{EFFECTS OF NITROGEN DEPOSITION AND CLIMATE CHANGE ON SCALED CHRYSOPHYTES IN LAKES DOWNWIND OF THE ATHABASCA OIL SANDS, CANADA}

List of Authors: Graham R. Mushet ${ }^{1}$, Kathleen R. Laird ${ }^{1}$, Biplob Das ${ }^{2}$, Brittany Hesjedal ${ }^{3}$, Peter R.

Leavitt $^{3,4}$, Kenneth A. Scott ${ }^{5}$, Gavin L. Simpson ${ }^{3}$, Bjöern Wissel ${ }^{3}$, Jared D. Wolfe ${ }^{3}$, Brian F. Cumming ${ }^{1}$

\section{Institutional affiliation:}

${ }^{1}$ Paleoecological Environmental Assessment and Research Laboratory, Dept. of Biology, Queen's University, 116 Barrie Street, ON, Canada, K7L 3N6

${ }^{2}$ Saskatchewan Water Security Agency, 3211 Albert Street, SK, Canada, S4S 5W6

${ }^{3}$ Limnology Laboratory, Dept. of Biology, University of Regina, 3737 Wascana Parkway, SK, Canada, S4S 0A2

${ }^{4}$ Institute of Environmental Change \& Society, Dept. of Biology, University of Regina, 3737 Wascana Parkway, SK, Canada, S4S 0A2

${ }^{5}$ Saskatchewan Ministry of Environment, 3211 Albert Street, SK, Canada, S4S 5W6

Corresponding author: Graham R. Mushet, M.Sc.

Mail: Paleoecological Environmental Assessment and Research Laboratory, Dept. of Biology, Queen's University, Kingston, ON, Canada

116 Barrie St. K7L 3N6

Telephone: 16135336000 ext. 79707

Email: gmushet1@gmail.com

Key words: Athabasca oil sands, nitrogen deposition, climate change, regional warming, scaled chrysophytes 


\begin{abstract}
Several limnological and paleolimnological investigations have linked enhanced atmospheric nitrogen (N) deposition to nutrient enrichment and potentially increased primary production. The Athabasca Oil Sands Region (AOSR) in northeast Alberta is a significant regional source of $\mathrm{N}$ emissions, particularly since development intensified during the 1990's, and recent paleolimnological investigations have provided some evidence of increased lake production in the AOSR. However, the AOSR has also experienced atmospheric warming and hydrological change since $c a 1900 \mathrm{AD}$, and therefore the relative effects of nutrient deposition and climatic mechanisms on lake production remain unclear. To address this problem, a factorial-designed paleolimnological assessment of 16 lakes in northwest Saskatchewan was undertaken to quantify changes in abundance and species composition of scaled chrysophytes over the past 100 years. Study sites included both N-limited and P-limited lakes within control regions as well as those receiving enhanced $\mathrm{N}$ deposition from the AOSR. We hypothesized that a change in algal communities within N-limited AOSR-impacted lakes, without concurrent changes in the other lake groups, would suggest AOSR-derived $\mathrm{N}$ as a driver of enhanced primary production. Instead, recent and marked increases in concentrations of scaled chrysophytes (mainly Mallomonas crassisquama) occurred in the recent sediments in cores from all four lake groups ( $\mathrm{N} \mathrm{v.} \mathrm{P}$ limited, impacted v. control), suggesting that regional climate changes rather than $\mathrm{N}$ deposition was the paramount process enhancing chrysophyte production. However, because chrysophyte abundances tended to be higher in deep, lower $\mathrm{pH}$ lakes, and chrysophyte time series were fit best by lake-specific generalized additive models (GAMs), we infer that climate effects may have additionally been meditated by catchment and/or lake-specific processes.
\end{abstract}




\section{Introduction}

The Athabasca Oil Sands Region (AOSR) in northeast Alberta, Canada, contains the third largest oil reserve on Earth, after Saudi Arabia and Venezuela. Development in the AOSR began in 1967, but accelerated during the 1990's due to increased demand for oil and reduced costs associated with production (Schindler 2010). The Canadian Association of Petroleum Producers (CAPP) expects production to reach $\sim 5$ million barrels per day (bpd) by the end of 2030 , in comparison to 2.2 million bpd in 2014 (CAPP 2015). Development in the AOSR includes operation of bitumen upgraders, open pit and in-situ mines, and diesel- and gas-powered machinery. These activities are sources of atmospheric pollutants including metals (Kelly et al. 2010; Laird et al. 2013), polycyclic aromatic hydrocarbons (Kurek et al. 2013), and nitrogen and sulfur oxides (NPRI 2015), while disturbance of the terrestrial environment also increases loading of dust and base cations into the atmosphere (Watmough et al. 2014). Concerns over the impacts of atmospheric deposition of these pollutants on nearby aquatic ecosystems has resulted in a number of monitoring programs including the Wood Buffalo Environmental Association (WBEA), the Cumulative Environmental Management Association (CEMA), and the Regional Aquatics Monitoring Program (RAMP). However, monitoring programs were introduced $\sim 30$ years after oil production in the AOSR began, and operate mainly in close proximity to Fort McMurray, Alberta, a city which is considered to be the centre of industrial activity in the oil sands. Instead, paleolimnological investigations have been used to provide longer-term records of change associated with industrial activity in the oil sands, particularly over concerns of acidic deposition (Hazewinkel et al. 2008; Curtis et al. 2010; Laird et al. 2013).

Many lakes in the AOSR and regions downwind have been identified as sensitive to the impacts of acidic deposition due to low acid neutralizing capacity (ANC) of the lake water. The Saskatchewan Ministry of the Environment (SKMOE) surveyed the water chemistry of 259 headwater lakes in northwest Saskatchewan between 2007 and 2008; 60\% of the lakes were categorized as acid sensitive

(50-200 $\mu \mathrm{eq} \mathrm{L} \mathrm{L}^{-1}$ ANC) and 8\% as very sensitive ( $<50 \mu \mathrm{eq} \mathrm{L}{ }^{-1}$ ANC) (Scott et al. 2010). Subsequent 
analysis of diatom assemblagesin sediment cores from ten of these lakes show that widespread lake acidification had not occurred to do AOSR development (Laird et al. 2013), a finding similar to sites in closer proximity to Fort McMurray (Hazenwinkel et al. 2008; Curtis et al. 2010). However, the findings from these studies suggest a number of lakes have experienced increases in primary production possibly due to nutrient enrichment and/or recent climate change.

Analysis of patterns in lake-water chemistry in Europe suggest that deposition of reactive nitrogen $\left(\mathrm{Nr}\right.$, in the forms $\left.\mathrm{NO}_{\mathrm{x}}, \mathrm{NH}_{\mathrm{x}}, \mathrm{N}_{2} \mathrm{O}\right)$ into lakes that are $\mathrm{N}$-limited may cause changes in species composition and production of planktonic communities due to $\mathrm{N}$ enrichment (Bergström et al. 2005; Bergström and Jansson 2006). Similarly, paleolimnological investigations of lakes in alpine regions of the western U.S., where many oligotrophic lakes are N-limited, have also documented post-1950 increases in mesotrophic diatom taxa that have been associated with enhanced $\mathrm{N}$ deposition (Baron et al. 2000; Wolfe et al. 2001; Saros et al. 2011). Although the boreal landscape where the AOSR is located is different from those of western alpine regions, the AOSR is a significant point source of nitrogen emissions, releasing approximately 312 tonnes day ${ }^{-1}$ of $\mathrm{NO}_{\mathrm{x}}$ (Deer Creek Energy Ltd. 2006). Though there have been relatively few studies investigating nitrogen deposition rates in northwestern Saskatchewan, Fenn et al. (2015) indicated that $\mathrm{N}$ deposition rates in our study region are likely between $\sim 1.1$ and $1.2 \mathrm{~kg} \mathrm{DIN} \mathrm{ha}^{-1} \mathrm{yr}^{-1}$. Within this impacted region, $\sim 25 \%$ of the lakes are potentially N-limited (DIN:TP $<1.5$ ) or co-limited by N and P (3.4> DIN:TP >1.5) (Scott et al. 2010), a pattern which suggests that many lakes may be sensitive to ecological changes arising from enhanced $\mathrm{N}$ deposition (Bergström 2010). To date, little is known of the ecological consequences of this AOSRderived $\mathrm{N}$, including its role as possible driver for regional increases in primary production.

Enhanced lake production has also been linked to recent changes in climate (reviewed in Adrian et al. 2009). For example, paleolimnological investigations in boreal and subarctic regions have documented shifts in lake biota, including scaled chrysophytes and diatoms that have been attributed to recent climate change (Wolfe and Perren 2001; Rühland et al. 2003, 2005). Such changes may arise 
from alterations in the duration of the growing season (Rühland et al. 2005), thermal structure of lakes (Ginn et al. 2010), variation in lake hydrology (McGowan et al. 2010), changes in DOC dynamics (Paterson et al. 2004; Hyatt et al. 2010), and elevated ${ }_{p} \mathrm{CO}_{2}$ in lakes, either due to warming-induced processes or rising atmospheric $\mathrm{CO}_{2}$ (Wolfe and Siver 2013). Similarly, paleolimnological investigations in the AOSR (Hazewinkel et al. 2008; Curtis et al. 2010) and in northern Saskatchewan (Laird et al. 2013) have also suggested that climate change may affect lake primary production, although the precise mechanism(s) has yet to be established. Taken together, these studies suggest that lakes downwind of the AOSR may be subject to effects of both nitrogen deposition and climate change.

The goal of the present paper is to quantify the importance of nutrient enrichment via atmospheric $\mathrm{N}$ deposition and climate change on production of scaled chrysophytes in lakes downwind of the AOSR. Unlike previous studies, we determined algal response in N- and P-limited lakes within both "reference" and "impacted" regions to isolate the importance of climatic and N-based mechanisms. Specifically, we hypothesized that if deposition of AOSR derived N was impacting lake primary production, chrysophyte response should be limited to N-limited lakes within the impact region. Additionally, we expected that if regional changes in climate or hydrology influenced chrysophyte assemblages, then these effects should be ubiquitous among study lakes.

\section{Methods}

Study design and lake selection

Between 2007 and 2011, the SKMOE sampled 262 lakes across the northwest region of Saskatchewan for water chemistry (Scott et al. 2010). The results from this water chemistry survey were used in the lake selection process for this study. All water sampling was conducted at the central or deepest location in each lake in autumn (September - October) to reduce spatial and temporal variability in chemistry within and among lakes. Water chemistry data was used to categorize lakes as potentially N- 
limited or P-limited based on the molar dissolved inorganic nitrogen to total phosphorus ratio (DIN:TP). According to Bergström (2010), nitrogen-limited lakes are defined by DIN:TP ratios $<1.5$, P-limited lakes by DIN:TP $>3.4$, and in between as either $\mathrm{N}$ or $\mathrm{P}$, or co-limited. This method has been considered advantageous over the more traditional TN:TP because TN often consist of refractory dissolved organic nitrogen (DON) compounds that are largely unavailable to phytoplankton (Bogard et al. 2012 and references therein), whereas DIN consists mainly of ammonium and nitrate which are forms of N preferred by algae (Wetzel 2001).

Study lakes were a priori chosen to be: i) N-limited or co-limited with P (DIN:TP $<3.4$ ), or ii) strongly P-limited (DIN:TP > 7). Lakes with multiple years of water chemistry data (208 of the 262 lakes had two or more measurements) were favored in the lake selection process, especially when there was minimal variability in DIN:TP ratios among years. In addition to DIN:TP ratios, lakes were selected to have a minimum depth of four meters. Although widespread lake acidification in the study region is unlikely (Scott et al. 2010; Laird et al. 2013), lakes with lower alkalinity values $\left(<5 \mathrm{mg} \mathrm{L}^{-1}\right)$ were avoided to minimize any potential confounding influence of acidic deposition.

To disentangle the potential impacts of changes in regional climate and $\mathrm{N}$ deposition, lakes with DIN:TP $<3.4$ (N-limited or N-P co-limited, referred to as N-limited hereafter) and DIN:TP $>7$ (Plimited) were separated into reference and impact regions (Fig. 1). The impact region is a zone of enhanced atmospheric deposition identified by Environment Canada using a regional air pollution forecast model (Environment Canada 2011) that integrates meteorological and emissions data to forecast transportation and deposition of atmospheric pollutants. The modeled deposition zone extends northeast from Fort McMurray and into northern Saskatchewan. Lakes in the reference region are outside the modeled enhanced deposition zone, either to the southeast or northeast, and both reference regions included lakes selected to have similar chemical and physical characteristics. This factorial design resulted in four categories of lakes: N-limited impact (NI) lakes, P-limited impact (PI) lakes, Nlimited reference (NR) lakes, and P-limited reference (PR) lakes. Based on the study design, 
disproportionate changes in scaled chrysophytes within NI lakes would suggest that $\mathrm{N}$ deposition may be impacting primary production in these lakes, whereas a similar changes in all lakes, irrespective of group, would suggest a response to a regional forcing factor such as regional warming.

Study lakes and regional site description

The sixteen study lakes from the four a priori groups (NI, PI, NR, PR) are mostly small $(<100$ ha) with the exception of $2 \mathrm{~F}, 9 \mathrm{C}, 10 \mathrm{Y}$ and $13 \mathrm{~N}$ which are closer to $\sim 150$ ha. Maximum depth $\left(Z_{\max }\right)$ ranged from $3.8 \mathrm{~m}$ to $28.7 \mathrm{~m}$ (Table I). Lakes are circumneutral (mean $\mathrm{pH}=7.1$; median $\mathrm{pH}=7.1$; range $=6.8$ to 7.3 ), relatively low in nutrients (mean total phosphorus $=10.1 \mu \mathrm{g} \mathrm{L}^{-1}$; median $=10.9 \mu \mathrm{g}$ $\mathrm{L}^{-1}$; range $=3.3-18.0 \mu \mathrm{g} \mathrm{L}^{-1}$ ), have low to moderate concentrations of DOC (mean DOC $=4.1 \mathrm{mg} \mathrm{L}^{-1}$; median $=3.8 \mathrm{mg} \mathrm{L}^{-1}$; range $\left.=1.6-7.1 \mathrm{mg} \mathrm{L}^{-1}\right)$, moderate to high alkalinity $\left(\right.$ mean $=10.5 \mathrm{mg} \mathrm{L}^{-1}$; median $=8.1 \mathrm{mg} \mathrm{L}^{-1}$; range $\left.=4.2-18.1 \mathrm{mg} \mathrm{L}^{-1}\right)$, and low specific conductivity $\left(\right.$ mean $=23.4 \mu \mathrm{S} \mathrm{cm}^{-1}$; median $=$ $20.0 \mu \mathrm{S} \mathrm{cm}^{-1}$; range $\left.=13.8-35.5 \mu \mathrm{S} \mathrm{cm}^{-1}\right)($ Table I). Interannual variation in nutrient chemistry is presented in Table SI in the Supplementary Material.

Impact sites are clustered along a northwest-southeast transect that spans $\sim 170 \mathrm{~km}$, with lakes located $\sim 150-200 \mathrm{~km}$ east of Fort McMurray (Fig. 1). Reference lakes are clustered $\sim 320 \mathrm{~km}$ northeast and $\sim 300 \mathrm{~km}$ due east of Fort McMurray. Most study lakes are located in the Boreal Shield ecozone, with the exception of 10Z, 10E, 6E and 10A which are located in the Boreal Plains ecozone. The portion of Boreal Shield in our study region is characterized by areas of exposed Precambrian crystalline bedrock with thin layers of overlying glacial till, glaciofluvial and glaciolacustrine deposits, and areas with a layer of younger sandstones, less basement rock exposure and thicker glacial deposits in the northern reaches near Lake Athabasca (Scott et al. 2010). Brunosolic soils are common in the study region, and luvisolic soils are found on silty and clayey glaciolacustrine deposits. Vegetation in the study region consists of jack pine (Pinus banksiana)/ lichen forest with balsam fir (Abies balsamea) 
and trembling aspen (Populus tremuloides) in well drained mineral soils, and black spruce (Picea mariana) in poorly drained regions. Regional climate is characterized as 'subarctic'. Mean annual air temperature and precipitation recorded in nearby Fort McMurray is $1.2^{\circ} \mathrm{C}$ and $487 \mathrm{~mm}$ (average 1980 2014), respectively. Mean winter and summer temperatures are $-15.0^{\circ} \mathrm{C}$ and $15.9^{\circ} \mathrm{C}$, respectively (average 1980-2014). In addition, mean annual air temperature recorded in Fort McMurray has increased from an average of $-1.1^{\circ} \mathrm{C}$ between 1916 and 1940 , to an average of $1.2^{\circ} \mathrm{C}$ between 1980 and 2014.

Sediment coring

Sediment cores were collected in February and March of 2014 from near the centre of most lakes using a Glew gravity corer (Glew et al. 2001) with an internal diameter of $\sim 7.6 \mathrm{~cm}$. Cores from all sites were sectioned into $0.5-\mathrm{cm}$ intervals and placed into individual Whirlpak ${ }^{\circledR}$ bags. Sediments were shipped to Queen's University where they were stored in a dark cold room (set to $4^{\circ} \mathrm{C}$ ) until processed for sedimentary analyses.

Core chronologies

${ }^{210} \mathrm{~Pb}$ dating was carried out on sediment cores from all study lakes via gamma spectroscopy at the Paleoecological Environmental Assessment Research Laboratory (PEARL), Queen's University, using procedures similar to Schelske et al. (1994). Samples for ${ }^{210} \mathrm{~Pb}$ analysis were spaced at $1-\mathrm{cm}$ intervals for the top $10-\mathrm{cm}$ of each core and at 2-cm intervals thereafter. Sediment samples were freeze-dried, packed into plastic tubes to $\sim 2 \mathrm{~cm}$ height, sealed with a 2-Ton epoxy and allowed to equilibrate $\left({ }^{214} \mathrm{Bi}\right.$ to ${ }^{226} \mathrm{Ra}$ ) for at least two weeks. Radioactive decay was measured for $80,000 \mathrm{~s}$ using an Ortec germanium (Gr) crystal-well detector. Activities of ${ }^{210} \mathrm{~Pb},{ }^{137} \mathrm{Cs}$ and supported ${ }^{210} \mathrm{~Pb}$ (via ${ }^{214} \mathrm{Bi}$ ) were determined for each sample based on calibration to internal standards IAEA 312 and 385 calibrated to 
tube heights that varied from 1 to $4 \mathrm{~cm}$. Chronologies were estimated based on unsupported ${ }^{210} \mathrm{~Pb}$ activities using the constant rate of supply (CRS) model in the ScienTissiME program (Mike Scheer, unpublished). Age-depth models were calculated in R version 3.1.2 (R Development Core Team 2010) using a cubic spline with a monotonicity constraint. The monotonic cubic spline does not force any specific polynomial form to the age model, and the monotonicity prevents reversals in depth-age relationships among adjacent samples.

Scaled-chrysophyte analysis

For each sample, $\sim 0.2-0.3 \mathrm{~g}$ of wet sediment was subsampled into a $20 \mathrm{~mL}$ glass vial. A 50:50 molar mixture of concentrated sulfuric and nitric acid was added and heated in a hot water bath at $\sim 75^{\circ} \mathrm{C}$ for 7-8 hrs to remove organic matter. After settling for $24 \mathrm{hrs}$, the samples were aspirated to $\sim 5 \mathrm{~mL}$ and then rinsed with double deionized water. This procedure was repeated until the sample reached the same $\mathrm{pH}$ as the double deionized water (7-8 rinses). The samples were then drawn down to $\sim 5 \mathrm{~mL}$. A known volume of microspheres (concentration $=2.0 \times 10^{7} \mathrm{spheres} / \mathrm{mL}$ ) was added to each sample to allow calculation of scaled-chrysophyte concentrations. Four successive dilutions for each sample were pipetted onto coverslips and were allowed to air-dry overnight. The coverslips were then heated on a warming plate to remove any remaining moisture, and permanently mounted onto glass microscope slides using Naphrax ${ }^{\circledR}$.

Chrysophyte scales and diatoms (see below) were enumerated on the same slides with a Leica DMRB microscope and a 100x oil immersion objective (numerical aperature $=1.3$ ) using differential interference contrast optics at 1000x magnification. Due to the low concentration and diversity of chrysophyte scales in most samples, for calculations of relative abundance at least 100 scales were counted. Counts of species composition were discontinued when less than 15 scales were counted on a single transect. Taxonomic identification of scales was based on standardized taxonomic literature including Nicholls and Gerrath (1985) and Siver (1991), and an unpublished reference collection at the 
PEARL lab. Chrysophyte concentrations were calculated relative to the artificial microspheres, following Battarbee et al. (2001). The scale-to-diatom index (S-to-D index) was calculated according to: [number of scales/(number of scales + number of diatom valves)] x 100, based on counts of at least 400 diatom valves.

Organic carbon content

Sediments were analyzed for percent organic carbon $(\% \mathrm{C})$ to assess major changes in sedimentation regimes or sediment in-wash events. Samples of 40-60 mg mass were first acidified to remove carbonate minerals by repeated exposure to $0.3 \mathrm{M} \mathrm{HCl}$. After acidification, sediments were washed with nanopure $\mathrm{H}_{2} \mathrm{O}$ until the $\mathrm{pH}$ was the same as that of the rinse water. Carbon content of acidified sediments was quantified by combustion, following methods of Savage et al. (2004). All elemental analyses were conducted at the Institute of Environmental Change and Society (IECS), University of Regina.

Statistical methods

Non-metric multidimensional scaling (nMDS) was used to reduce the complexity of the lake physical and chemical environmental data (Clark and Warwick 2001), and assess the overall relative similarity of the sixteen study lakes in two-dimensional (2D) ordination space. nMDS was based on a distance matrix using Euclidean distances, which is appropriate because the dataset did not include null values. The nMDS was performed using square root-transformed physical and chemical environmental variables.

The ratios of scales to diatoms (S-to-D index) were used to quantify the historical changes in the abundance of scaled chrysophytes. However, because both the numerator and denominator can 
affect the ratio, Pearson correlation coefficients were calculated for each core to assess how changes in sedimentary concentrations of chrysophyte scales affected the S-to-D index. Significant and positive correlations between the two metrics were interpreted to indicate that fluctuations in chrysophyte abundance are regulating variation in the S-to-D index.

Generalized Additive Models (GAMs) were used to test whether changes in gross composition of siliceous algae (S-to-D index) exhibited common trends through time within each of the four lake groups (NI, PI, NR, and PR). Two classes of GAMs were evaluated; a lake model which evaluated whether changes in the S-to-D index were lake-specific, and a factorial model that assumed four lakeresponse groups according to the factorial study design ( $\mathrm{N}$ - and P-limited; impact and reference). Each model had three terms including the central response, a categorical smoothing spline term (thin platesmoothing spline), and a lake-specific term to quantify departures from the categorical (common) trends. The relative fit of lake and factorial models was evaluated based on degrees of freedom (DF) and Bayesian Information Criterion (BIC). BIC is based on the log-likelihood function and does not require the specification of priors (Schwarz 1978). Overall, the model with the lowest BIC value is considered to perform best. Models were fitted using the R programming language (version 3.1.2; R Development Core Team 2010) with the mgcv package (Wood 2016).

Lastly, an additional exploratory analysis was undertaken to explore the relationship between scaled-chrysophyte abundance and the physical and chemical characteristics of the lakes. To do this, the maximum scale concentration in the top of each sediment core was classified as high, medium, or

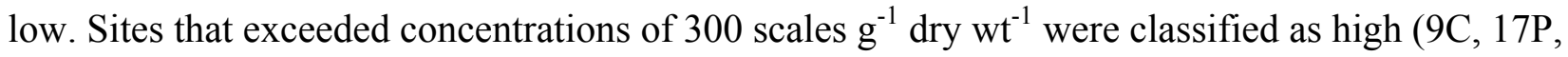
$17 \mathrm{~F}$ ), sites that had concentrations between 30 and 300 scales $\mathrm{g}^{-1} \mathrm{dry}_{\mathrm{wt}} \mathrm{t}^{-1}$ were classified as medium $(2 \mathrm{Q}, 13 \mathrm{~L}, 13 \mathrm{~N}$ and $6 \mathrm{E})$, and sites that did not exceed 30 scales $^{-1}$ dry $\mathrm{wt}^{-1}$ were classified as low $(17 \mathrm{~J}$, $2 \mathrm{~F}, 11 \mathrm{G}, 17 \mathrm{~V}, 10 \mathrm{~A}, 2 \mathrm{~L}, 10 \mathrm{E}, 10 \mathrm{Y}$ and 10Z). A canononical variate analysis (CVA) was then performed to identify environmental variables that could separate the three a priori defined groups of chrysophyte 
scale abundance. CVA was run in CANOCO v.5. using forward selection (ter Braak and Šmilauer 2012). Environmental variables were log transformed if appropriate.

\section{Results}

Lake Selection

The selection of the majority of the study lakes was based on two or more water chemistry samples, with only four of our study lakes based on a single sample (9C, 10Z, 10E and 10Y). Non-metric multidimensional scaling (nMDS) ordination of the physical and chemical variables of the study lakes confirmed that the DIN:TP ratio was a central variable separating the lakes in ordination space, regardless of the designation as an impact or reference site. The impact and reference N-limited lakes plot to the left side of the ordination, whereas the P-limited sites plot to the right side (Fig. 2). Within the nMDS, the physical and chemical characteristics of the reference and impact sites overlap (Fig. 2).

Core chronologies

The majority of cores showed good $\left(r^{2}>0.8<0.9\right)$ to very good $\left(r^{2}>0.9\right)$ first order exponential decay of total ${ }^{210} \mathrm{~Pb}$ activity, suggesting that strong age-depth models could be developed (Fig. S1 in Supplementary Material). Lakes 10Y and 2L are exceptions as their $r^{2}$ values are lower, 0.72 and 0.69 respectively, indicating their chronologies need to be interpreted with more caution. Background (supported) levels of ${ }^{210} \mathrm{~Pb}$ were reached at a range of depths in the sixteen sediment cores: $25-35 \mathrm{~cm}$ $(2 \mathrm{~F}, 2 \mathrm{Q}, 6 \mathrm{E}, 10 \mathrm{E}), 15-25 \mathrm{~cm}(2 \mathrm{~L}, 9 \mathrm{C}, 17 \mathrm{~J}, 17 \mathrm{~V})$ and 5-15cm (10A, 11G, 13L, 13N, 17F, 17P). Lake $10 \mathrm{Y}$ did not reach background levels of ${ }^{210} \mathrm{~Pb}$ until $40 \mathrm{~cm}$. The majority of lakes had sufficient sedimentation rates to achieve the desired decadal to sub-decadal temporal resolution since $\sim 1900$ for scaled-chrysophyte analysis, with analysis undertaken at either $0.5-\mathrm{cm}$ or $1-\mathrm{cm}$ intervals. Two 
exceptions were Lakes 17P and 17F, which had lower sedimentation rates and a temporal resolution closer to $\sim 12-15$ years was only possible. Some cores showed evidence of increased sedimentation and/or mixing in the uppermost samples (e.g. Lakes 6E, 10E, $10 \mathrm{Y}$ and $2 \mathrm{~F}$ ), however there are at least two cores in each of the four a priori lake groups with little evidence of potential mixing, suggesting that timing of changes should be accurately represented across all groups (Fig S1. in Supplementary Material).

Scaled-chrysophyte species assemblages

Sediment cores from eight of the sixteen lakes had sufficient concentrations for enumeration and identification of scaled chrysophytes to the species level: 6E and 9C (NI lakes), 10A, 13N and 13L (PI lakes), 2Q (NR lake), and 17P and 17F (PR lakes). A total of 15 scaled-chrysophyte taxa were identified throughout these sediment cores, and were predominantly taxa of the unicellular genus Mallomonas. M. crassisquama (Asmund) Fott was the predominant taxon in all cores, exhibiting relative abundances ranging from 40-90\% (Fig. 3). In Lake 13L, which is one of the deepest lakes in this study $\left(Z_{\max }=26.2 \mathrm{~m}\right)$, Mallomonas lychensis Conrad was the main scaled-chrysophyte taxon, accounting for $\sim 40 \%$ of the assemblage. Other common Mallomonas included M. duerrschmidtiae Siver, Hamer and Kling, M. pseudocoronata Prescott and M. caudata Ivanov. Taxa of the colonial genus Synura were only seen in some cores $(6 \mathrm{E}, 10 \mathrm{~A}, 13 \mathrm{~L}, 17 \mathrm{P})$ at low relative abundances $(<15 \%)$, with the exception of $17 \mathrm{P}$ which included S. uvella Ehrenberg as $\sim 20 \%$ of the assemblage in some intervals (Fig. 3).

Chrysophyte species composition changed little since $c a 1900 \mathrm{AD}$ in most lakes (Fig. 3). One exception, Lake 9C, exhibited a decline in M. pseudocoronata from $\sim 40 \%$ relative abundance ca. 1980 AD to $\sim 5 \%$ after ca. 2001 AD. Lake 13L also showed a decline in M. lychensis post ca. 2000 AD (Fig. 3). In contrast, total concentrations of fossil scales increased in most cores (Fig. 4), although the 
absolute magnitude and timing of the increases varied among sites. Scale concentrations were highest in the top of $9 \mathrm{C}$ and $17 \mathrm{P}$ near $\sim 500 \times 10^{7}$ scales $\mathrm{g}^{-1}$ dry weight, while the maximum scale

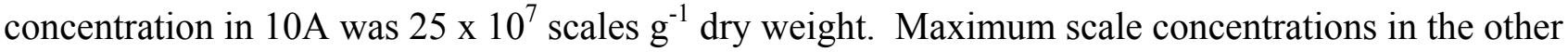
five cores ranged from 140 to $300 \times 10^{7}$ scales $^{-1}$ dry wt (Fig. S2 in Supplementary Material). Overall, scale concentrations were significantly $(p<0.001)$ and positively correlated $\left(0.78<r^{2}<0.98\right)$ to changes in the S-to-D index in all lakes (Table SII in Supplementary Material).

Percent organic carbon

Organic C content ranged between 10-45\% among lakes (Fig S2. in Supplementary Material). There were no consistent temporal changes in $\% \mathrm{C}$ in any lake group during the $20^{\text {th }}$ century, with the exception of three of the PI lakes (10A, $13 \mathrm{~N}$ and $11 \mathrm{G})$ which showed a trend towards lower \%C in the recent sediments. In addition, some sites exhibited highly variable carbon content $(6 \mathrm{E}, 10 \mathrm{E}, 17 \mathrm{~V})$, while others showed little fluctuation through time (e.g. 2Q, 17P, 17F).

Generalized Additive Models (GAMs)

The Factorial model indicated that historical changes in the S-to-D index were significant across all lake groups $(\alpha<0.05)$, with the exception of the PR group $(\alpha>0.05<0.1)$ (Table II). The GAM smoothers extracted from each lake group (i.e. the common trend) also indicated that the S-to-D index increased significantly in each of the four lake groups (Fig S3. in Supplementary Material). Model evaluation indicated that the Lake model explained a similar amount of variation as the Factorial model (85.5\% and 86\%, respectively), while using fewer degrees of freedom (62.0 and 68.0, respectively). The Lake model also had a lower Bayesian Information Criteria than the Factorial model (1304 and 1328, respectively) (Table II). The change through time in the S-to-D index predicted by 
GAM smoothers in the Lake model indicated coherent late $20^{\text {th }}$ century ( $c a 1980$ AD) increases in chrysophyte abundance in the majority of the sixteen study lakes, though the magnitude of the increases vary between lakes (Fig. 4).

\section{Exploratory CVA}

CVA explained $71 \%$ of the variance in the concentration of chrysophyte scales in surface sediments on the first two axes $\left(\lambda_{1}=0.60, \lambda_{2}=0.11\right)$. Maximum lake depth $\left(Z_{\max }\right)$ was the only significant physical/chemical variable that could distinguish among lakes on the basis of surface scale sediment scale concentrations (low, medium, high). CVA with depth explained $25.4 \%$ of the variation in scale concentrations $(p=0.01)$. Although $\mathrm{pH}$ also explained $10.2 \%$ of scale density variation, the prediction was not statistically significant $(p=0.14)$, but it was retained in the CVA ordination as an active

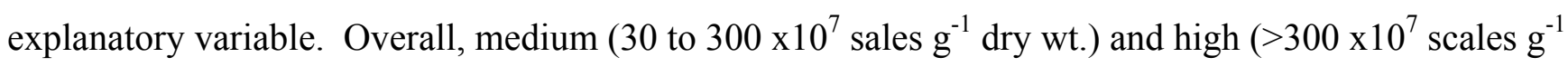
dry wt.) chrysophyte abundances tended to occur in deeper (mean $Z_{\max }=14.1 \mathrm{~m}$ ) and circumneutral

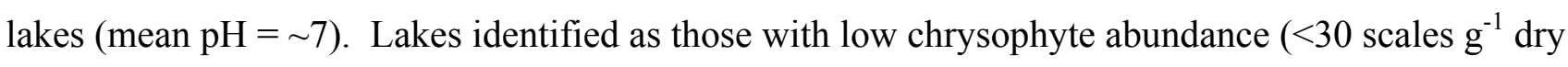
wt.) tended to be shallower (mean $\mathrm{Z}_{\max }=7.9 \mathrm{~m}$ ) and slightly higher $\mathrm{pH}$ lakes (mean $\mathrm{pH}=7.1$ ), though the $\mathrm{pH}$ gradient is short.

\section{Discussion}

Analysis of historical changes in the species composition and abundance of scaled chrysophytes revealed increases in production of this phytoplankton group during the $20^{\text {th }}$ century, irrespective of the reference or impact or $\mathrm{N}$ - or P-limited lake grouping. In all lakes, M. crassisquama was the dominant taxon, a species which is common in many lakes because they occur across a large range of important environmental variables, including nutrients, temperature, and $\mathrm{pH}$ (Siver 1991, 1995). In addition, 
there was very little change in the historical composition of scaled-chrysophyte assemblages (Fig. 3). Instead, marked increases in chrysophyte abundance occurred in the majority of study lakes and across all four a priori groups during the last half of the $20^{\text {th }}$ century (Fig. 4). Together, these patterns suggest that chrysophyte communities were not responding to the deposition of $\mathrm{N}$ from the AOSR. Rather, the spatially coherent increases in the abundance of scaled chrysophytes in the recent sediments in a number of the study lakes (Fig. 4; Fig. S3 in Supplementary Material) is more consistent with the operation of a regional control, such as atmospheric warming or changes in hydrological controls.

$\mathrm{N}$ deposition and chrysophyte ecology

Chrysophytes are often considered to be more competitive in nutrient-poor water due to their small size and large surface area to volume ratio (Sandgren 1988, Siver 1995). For example, in a survey of 15 unproductive lakes in Wyoming, United States, chrysophytes were shown to prefer low-N conditions, as they accounted for a higher proportion of the total algal assemblage in lakes with low $\mathrm{N}$ concentrations than in lakes with high $\mathrm{N}$ concentrations (Lafrancois et al. 2003). In addition, $\mathrm{N}$ additions to mesocosm experiments in nitrate-poor lakes of the Colorado Front Range initiated a shift in phytoplankton species from chrysophytes towards chlorophytes, cyanophytes and diatoms (Baron et al. 2005). A number of other lake surveys have also associated chrysophytes with low nutrient conditions (Schindler and Holmgren 1971; Eloranta 1986; Siver and Chock 1986). Given their preference for oligotrophic conditions, the historical increase in scaled chrysophytes in our study lakes is inconsistent with the effects of fertilization through $\mathrm{N}$ deposition (Fig. 4; Fig. S2 in Supplementary Material). This qualitative interpretation of the scaled-chrysophyte abundance data is also supported by the results from the GAM analysis which indicated that gross changes in the abundance of chrysophytes (as S-to-D index) changed significantly in three of four lake impact groups, with the exception of the PR group $(\alpha>0.05<0.1)$, in the late $20^{\text {th }}$ century (Table II; Fig. S3 in Supplementary 
Material). However, because the GAM model selection process also indicated that lake-specific models best explained variation in the S-to-D index (lower BIC, fewer degrees of freedom used), we infer that climate effects may be moderated through variation in site-specific characteristics, such as lake morphology (Kraemer et al. 2015) or catchment filter characteristics (Blenckner 2005; Leavitt et al. 2009).

We also infer that deposition of $\mathrm{N}$ from the AOSR did not alter chrysophyte abundance via indirect biogeochemical mechanisms. For example, acidic deposition can increase the availability of $\mathrm{Al}$ and Fe minerals in soils, and consequently increase $\mathrm{P}$ adsorption, thereby reducing $\mathrm{P}$ export to lakes and streams (McDowell et al. 2002). A recent study by Arseneau (2014) suggested that the oligotrophication of lakes in the Adirondack (NY) region as a result of this process may have played a role in a change in scaled-chrysophyte assemblages since $c a 1900 \mathrm{AD}$. Although enhanced terrestrial P adsorption due to soil acidification and subsequent declines in lake-water P may be favourable for scaled-chrysophyte production, this is an unlikely mechanism in northern Saskatchewan as multiple paleolimnological investigations in the AOSR and northern Saskatchewan provide little evidence of widespread acidification (Hazewinkel et al. 2008; Curtis et al. 2010; Laird et al. 2013). The reason for lack of acidic deposition related effects in lakes and their catchments is uncertain, although it has been suggested that deposition of base cations from atmospheric sources may neutralize the effects of acid influx (Watmough et al. 2014).

The limited response of scaled chrysophytes to deposition of AOSR- derived N may arise because $\mathrm{N}$ influx to northwest Saskatchewan is less than that required to initiate a critical ecosystem change. Saros et al. (2011) determined that a critical load of $1.4 \mathrm{~kg} \mathrm{~N} \mathrm{ha}^{-1}$ year $^{-1}$ of wet $\mathrm{N}$ deposition was required to elicit changes in diatom production in response to nutrient enrichment in alpine lakes of the western United States. Additionally, Baron (2006) used a combination of fossil diatom analysis and hindcast models to estimate that the critical threshold for diatom community change was also $\sim 1.5$ $\mathrm{kg} \mathrm{N} \mathrm{ha}^{-1}$ year $^{-1}$ in the Colorado Front Range. In contrast, recent work by Fenn et al. (2015) showed 
that deposition of DIN from the AOSR declined exponentially with distance from the industrial center near Fort McMurray (Fig. 1), and reached values of 1.1 and $1.2 \mathrm{~kg} \mathrm{ha}^{-1} \mathrm{yr}^{-1}$ (canopy and open sites, respectively) at a downwind distance similar to that of our study sites (110-130 km). These measurements are somewhat lower than the previous estimates of critical nitrogen deposition loads to elicit algal responses in the western United States (Baron et al. 2006; Saros et al. 2011). In addition, the alpine regions of the western United States are characterized by little upstream vegetation and steep topography which create low saturation and leaching thresholds. In contrast, northwest Saskatchewan is relatively heavily forested and has low relief, and may be efficient at storing additional $\mathrm{N}$ and preventing further leaching into water bodies. Finally, consistent with the hypothesis that chrysophytes are not responding to $\mathrm{N}$ deposition, we note that increases in algal abundance also appear to occur before the substantial expansion of N emissions in the 1990's in a number of the lakes (Fig. 4; Fig. S2 in Supplementary Material).

Climate change

Increases in scaled chrysophyte microfossils (stomatocysts and scales) and major assemblage changes have been observed during the $20^{\text {th }}$ century in many regions, including the mid and high Arctic (Wolfe and Perren 2001; Wolfe and Siver 2013), eastern Canada (Ginn et al. 2010), subarctic and Boreal regions (Laird et al. 2013; Wolfe and Siver 2013), and south-central and northern Ontario (Paterson et al. 2004; Flear 2011). Such regional changes are often associated with reorganization of climate systems, although the precise mechanism underlying the change is either unknown or may vary among regions.

Climate change, including regional warming, may favour increased abundance of scaled chrysophytes in northern Saskatchewan. Temperature records from Fort McMurray indicate that mean annual air temperatures have increased by $\sim 2.3^{\circ} \mathrm{C}$ since the early 1900 's (Environment Canada). 
Warming can change the timing of ice-out on lakes, create longer and stronger periods of thermal stratification, ultimately resulting in changes in algal production and composition (Adrian et al. 2009). These conditions may provide motile (flagellated) algae, such as chrysophytes, a competitive advantage over non-motile algae because they can seek out optimal temperature, nutrient and light conditions within the water column (Winder and Sommer 2012). Under more mixed conditions, this advantage is reduced as non-flagellated algae, including diatoms, have the ability to remain suspended in the water column and compete for light and nutrients. Our CVA of surficial scale concentrations (high, medium, low) also identified maximum depth as the only significant variable separating these three groups. This pattern is consistent with effects of regional warming as a driver of chrysophyte population expansion because deeper lakes may be less prone to wind induced mixing, yet are expected to experience the largest changes in thermal stability in response to warming (Adrian et al. 2009; Kraemer et al. 2015).

In general, our findings are consistent with those of Laird et al. (2013) and Wolfe and Siver (2013) who also documented marked increases in Mallomonas scales from lakes in northern Alberta and northern Saskatchewan. The consistency in the timing of increased chrysophyte abundance across this region further suggests a regional stressor, such as climate, as a driver of these changes (Fig. 4). However, we also note that lake morphometry may have interactive effects with climatic mechanisms, as deep and circumneutral lakes showed a larger response of chrysophytes than in shallow more alkaline systems. Additionally, as noted by Blenckner (2005), individual lake catchments may act as site-specific filters of climatic forcing, resulting in differences of individual basins to a common forcing mechanism. However, it is presently difficult to identify which catchment features might be act as climate filters, and we recommend further analysis of a larger number of lakes.

Regional increases in the abundance of scaled chrysophytes may also reflect regulation by other climatic mechanisms. For example, Wolfe and Siver (2013) have suggested that increased $p \mathrm{CO}_{2}$ arising from elevated lake temperatures, DOM influx, or atmospheric $\mathrm{CO}_{2}$ content may favour the production of chrysophytes which do not possess the carbon-concentrating mechanism that is needed to 
compete with other algae in low $\mathrm{CO}_{2}$ environments (Raven et al. 2005). Although the number of study lakes in the current investigation is low, we currently do not favour this explanation for chrysophyte population expansion because scale concentrations in modern sediments are unrelated $\left(r^{2}=0.15, p>\right.$ $0.1)$ to modern $p \mathrm{CO} 2$ in our lakes, even when calculated using the same methods as Wolfe and Siver (2013). Similarly, while regional changes in seasonal precipitation may influence lake ecosystems, we currently lack basin-specific data on runoff processes. To address this issue, future studies will use stable isotopes to evaluate historical changes in regional hydrology (cf. McGowan et al. 2010).

Representation and interpretation of microfossils

In principle, the abrupt increases in chrysophyte concentrations in recent decades in many of the lakes could arise from diagenetic dissolution of siliceous remains. Poor preservation of siliceous microfossils is sometimes recorded in lakes with high $\mathrm{pH}$ or salinity (Barker et al. 1990). However, this mechanism appears unlikely in these dilute lakes, as scales were well preserved throughout the sediment cores from all sites and showed few signs of pitting or disarticulation, even within the lightly silicified components of some scales (e.g., anterior wing on M. pseudocoronata). Similarly, there was little evidence of diagenetic dissolution in diatoms, and a well-preserved flora existed prior to the increase in scale abundance in our cores (Laird, unpublished data). If dissolution and poor preservation of the microfossils was a factor, the chrysophytes and the diatoms should both be affected.

Changes in sedimentation, such as large influx of allochthonous material and changes in sedimentation accumulation rates can also influence the accumulation of microfossils in sediments (Battarbee et al. 2001). Estimates of organic carbon were used as an additional independent line of evidence of changes in sedimentation in our study lakes, and were plotted with chrysophyte scale concentrations to facilitate comparison (Fig. S2 in Supplementary Material). Although some profiles are highly variable through time (e.g. $17 \mathrm{~V}$ and $10 \mathrm{Y}$ ), there are no consistent directional trends in C 
content, suggesting that changes in organic sedimentation is likely not a controlling factor on chrysophyte scale concentration. Therefore, the recent increases in scaled-chrysophyte abundance is not considered to be an artifact of poor preservation and/or changes in sedimentation, but a reflection of other important limnological variables that are responding to environmental change.

\section{Conclusions}

This investigation was the first to study potential nutrient enrichment effects on algal production from $\mathrm{N}$ deposition in lakes downwind of the AOSR in northwest Saskatchewan. Application of a factorial design and GAM analysis demonstrated that chrysophyte populations in northwest Saskatchewan lakes are presently not responding to enhanced $\mathrm{N}$ deposition. Instead, we find that increases in scaled chrysophytes observed in eight lakes across the study region are more consistent with a regional forcing mechanism, such as changes in lake warming or hydrology. The significant relationship between fossil scaled-chrysophyte abundances in recent sediments and lake depth identified in a canonical variate analysis (CVA) provides further evidence that regional (climatic) processes, in combination with a lake specific response, may be regulating chrysophyte production. Together, these findings suggest that emissions from industrial activity in the AOSR are not currently having a detectable influence on siliceous primary producers on downwind lakes in northwest Saskatchewan. Monitoring should continue in this region to identify potential future industrial influences as well as climate related impacts. 


\section{References}

Adrian R, O'Reilly CM, Zagarese H, Baines SB, Hessen DO, Keller W, Livingstone DM, Sommaruga R, Straile D, Van Donk E, Weyhenmeyer GA, Winder M (2009) Lakes as sentinels of climate change. Limnol Oceanogr 54: 2283-2297

Arseneau (2014) Acidification and climate warming: understanding the impact of multiple anthropogenic stressors on Adirondack (NY, USA) lakes. PhD Dissertation. Queen's University Kingston, Ontario.

Barker P, Gasse F, Roberts N, Taieb M (1990) Taphonomy and diagenesis in diatom assemblages; a Late Pleistocene paleoecological study from Lake Magadi. Hydrobiologia 214: 267-272

Baron JS, Rueth HM, Wolfe AM, Nydick KR, Allstott EJ, Toby Minear J, Moraska B (2000) Ecosystem responses to nitrogen deposition in the Colorado Front Range. Ecosystems 3: 352-368

Baron JS, Nydick KR, Rueth HM, Moraska Lafrancois B, Wolfe AP (2005) High elevation ecosystem responses to atmospheric deposition of nitrogen in the Colorado Rocky Mountains, USA In: Huber UM, Bugmann HKM, Reasoner MA (ed) Global Change and Mountain Regions. Springer, Dordrecht, Netherlands

Baron JS (2006) Hindcasting nitrogen deposition to determine an ecological critical load. Ecol Appl 16: $433-439$

Battarbee RW, Jones VJ, Flower RJ, Cameron NG, Bennion H (2001) Diatoms. In: Smol JP, Birks HJB, Last WM (ed) Tracking Environmental Change Using Lake Sediments. Volume 3: Terrestrial, Algal, and Siliceous Indicators. Kluwer Academic Publishers, Dordrecht, The Netherlands

Bergström A (2010) The use of TN:TP and DIN:TP ratios as indicators for phytoplankton nutrient limitation in oligotrophic lakes affected by $\mathrm{N}$ deposition. Aquat Sci 72: 277-281

Bergström A-K, Blomqvist P, Jansson M (2005) Effects of atmospheric nitrogen deposition on nutrient limitation and phytoplankton biomass in unproductive Swedish lakes. Limnol Oceanogr 50: 987994

Bergström A-K, Jansson M (2006) Atmospheric nitrogen deposition has caused nitrogen enrichment and eutrophication of lakes in the northern hemisphere. Glob Change Biol 12: 635-643

Blenckner T (2005) A conceptual model of climate-related effects on lake ecosystems. Hydrobiologia 533: $1-14$

Bogard MJ, Donald DB, Finlay K, Leavitt PR (2012) Distribution and regulation of urea in lakes of central North America. Freshw Biol 57: 1277-1292

CAPP (2015) Canadian Association of Petroleum Producers. Crude Oil: Forecast, Markets and Transportation. Available online at: http://www.capp.ca/publications-and-statistics/crude-oil-forecast 
Clark KR and Warwick RM (2001) Change in marine communities: an approach to statistical analysis and interpretation, $2^{\text {nd }}$ edn. Primer-e, Plymouth

Curtis CJ, Flower R, Rose N, Shilland J, Simpson GL, Turner S, Yang H, Pla S (2010)

Palaeolimnological assessment of lake acidification and environmental change in the Athabasca

Oil Sands Region, Alberta. J Limnol 69: 92-104

Deer Creek Energy Ltd (2006) Joslyn North Mine Project: integrated application to Alberta Environment and the Alberta Energy and Utilities Board. Prepared for Total E\&P Canada Limited, Calgary. Available through the Alberta Government Library. Edmonton, Alta

Eloranta P (1986) Phytoplankton structure in different lake types in central Finland. Holarct Ecol 9: 214-224

Environment Canada (2011) Integrated Monitoring Plan for the Oil Sands; Air Quality Component. Available from: http://www.ec.gc.ca/default.asp?lang=En\&n=56D4043B-1\&news=7AC1E7E281E0-43A7-BE2B-4D3833FD97CE

Fenn ME, Bytnerowicz A, Schilling SL, Ross CS (2015) Atmospheric deposition of nitrogen, sulfur and base cations in jack pine stands in the Athabasca Oil Sands Region, Alberta, Canada. Environ Pollut 196: 497-510

Flear K (2011) Changes in scaled-chrysophyte assemblages in response to recent climate change in Northwestern Ontario. MSc. Dissteration. Queen's University Kingston, Ontario

Ginn BK, Rate M, Cumming BF, Smol JP (2010) Ecological distribution of scaled-chrysophyte assemblages from the sediments of 54 lakes in Nova Scotia and southern New Brunswick, Canada. J Paleolimnol 43: 293-308

Glew JR, Smol JP, Last WM (2001) Sediment core collection and extrusion. In: Last WM, Smol JP (eds) Tracking Environmental Change Using Lake Sediments, Vol. 1, Basin Analysis, Coring, and Chronological Techniques. Kluwer Academic Publishers, Dordrecht

Hazewinkel RRO, Wolfe AP, Curtis C, Hadley K (2008) Have atmospheric emissions from the Athabasca Oil Sands impacted lakes in northeastern Alberta, Canada? Can J Fish Aquat Sci 65: 1554-1567

Hyatt CV, Paterson AM, Cumming BF, Smol JP (2010) Factors related to regional and temporal variation in the distribution of scaled chrysophytes in north-eastern North America: Evidence from lake sediments. Nova Hedwigia Beih 136: 87-102

Kelly EN, Schindler DW, Hodson PV, Short JW, Radmanovich R, Nielsen CC (2010) Oil sands development contributes elements toxic at low concentrations to the Athabasca River and its tributaries. Proceedings of the National Academy of Sciences 107: 16178-16183

Kurek J, Kirk JL, Muir DCG, Wang X, Evans MS, Smol JP (2013) Legacy of a half century of Athabasca oil sands development recorded by lake ecosystems. Proceedings of the National Academy of Sciences 110: 1761-1766 
Kraemer BM, Anneville O, Chandra S, Dix M, Kuusisto E, Livingstone DM, Rimmer A, Schladow SG, Silow E, Sitoki LM, Tamatamah R, Vadeboncoeur Y, McIntyre PB (2015) Morphometry and average temperature affect lake stratification responses to climate change. Geophys Res Lett 42: 4981-4988

Lafrancois BM, Nydick KR, Caruso B (2003) Influence of nitrogen on phytoplankton biomass and community composition in fifteen Snowy Range Lakes (Wyoming, U.S.A.). Arct Antarct Alp Res 35: 499-508

Laird KR, Das B, Kingsbury M, Moos MT, Pla-Rabes S, Ahad JME, Wiltse B, Cumming BF (2013) Paleolimnological assessment of limnological change in 10 lakes from northwest Saskatchewan downwind of the Athabasca oils sands based on analysis of siliceous algae and trace metals in sediment cores. Hydrobiologia 720: 55-73

Leavitt PR, Fritz SC, Anderson NJ, Baker PA, Blenckner T, Bunting L, Catalan J, Conley DJ, Hobbs W, Jeppesen E, Korhola A, McGowan S, Rühland K, Rusak JA, Simpson GL, Solovieva N, Werne J (2009) Paleolimnological evidence of the effects on lakes of energy and mass transfer from climate and humans. Limnol Oceanogr 54: 2330-2348

McDowell RW, Brookes PC, Mahieu N, Poulton PR, Johnston AE, Sharpley AN (2002) The effects of soil acidity on potentially mobile phosphorus in a grassland soil. J Agric Sci 139: 27-36

McGowan S, Leavitt PR, Hall RI, Wolfe BB, Edwards TWD, Karst-Riddoch T, Vardy SR (2011) Interdecadal declines flood frequency increase lake primary production in a northern river delta. Glob Change Biol 17: 1212-1224

Nicholls KH, Gerrath JF (1985) The taxonomy of Synura (Chrysophyceae) in Ontario with special reference to taste and odour in water supplies. Can J Bot 63: 1482-1493

NPRI (2015) National Pollutant Release Inventory, Environment Canada. Available from https://www.ec.gc.ca/inrp-npri/

Paterson AM, Cumming BF, Smol JP, Hall RI (2004) Marked recent increases of colonial scaled chrysophytes in boreal lakes: implications for the management of taste and odour events. Freshw Biol 49: 199-207

R Development Core Team (2010) R: A Language and Environment for Statistical Computing. Vienna, Austria: R Foundation for Statistical Computing. Available online at: http://www.R-project.org/

Raven JA, Ball LA, Beardall J, Giordano M, Maberly SC (2005) Algae lacking carbon concentrating mechanisms. Can J Bot 83: 879-890

Rühland K, Priesnitz A, Smol JP (2003) Paleolimnological evidence from diatoms for recent environmental changes in 50 lakes across Canadian arctic treeline. Arct Antarct Alp Res 35: 110123

Rühland K, Smol JP (2005) Diatom shifts as evidence for recent Subarctic warming in a remote tundra lake, NWT, Canada. Palaeogeogr Palaeoclimatol Palaeoecol 226: 1-16 
Sandgren CD (1988) The ecology of Chrysophyte flagellates: their growth and perennation strategies as freshwater phytoplankton. In: Sandgren CD. (ed) Growth and Reproductive Strategies of Freshwater Phytoplankton. Cambridge University Press, Cambridge, pp 9-104

Saros JE, Clow DW, Blett T, Wolfe AP (2011) Critical nitrogen deposition loads in high-elevation lakes of the western US inferred from paleolimnological records. Water Air Soil Pollut 216: 193202

Savage C, Leavitt PR, Elmgren R (2004) Distribution and retention of sewage nitrogen in surface sediments of a coastal bay. Limnol Oceanogr 49: 1503-1511

Schelske CL, Peplow A, Brenner M, Spencer CN (1994) Low-background gamma counting: applications for ${ }^{210} \mathrm{~Pb}$ dating of sediments. J Paleolimnol 10: 115-128

Schindler DW (2010) Tar sands need solid science. Nature 468: 499-501

Schindler DW and Holmgren SK (1971) Primary production and phytoplankton in the Experimental Lakes Area, northwestern Ontario, and other low-carbonate waters, and a liquid scintillation method for determining ${ }^{14} \mathrm{C}$ activity in photosynthesis. J Fish Res Board Can 28: 189-201

Schwarz G (1978) Estimating the dimension of a model. Ann Stat 6: 461-464.

Scott KA, Wissel B, Gibson JJ, Birks SJ (2010) Chemical characteristics and acid sensitivity of boreal headwater lakes in northwest Saskatchewan. J Limnol 69: 33-44

Siver PA (1991) The Biology of Mallomonas. Kluwer Academic Publishers, Dordrecht, The Netherlands

Siver PA (1995) The distribution of chrysophytes along environmental gradients: their use as biological indicators. In: Sandgren CD, Smol JP, Kristiansen J (eds) Chrysophyte algae: Ecology, phylogeny and development. Cambridge University Press, Cambridge, UK, pp 232-268

Siver PA and Chock JS (1986) Phytoplankton dynamics in a chrysophycean lake. In: Kristiansen J, Andersen RA (eds) Chrysophytes: Aspects and Problems. Cambridge University Press, Cambridge, pp 165-183

ter Braak CJF, Šmilauer P (2012) CANOCO reference manual and user's guide: software for ordination (version 5.0). Microcomputer Power, Ithaca, New York

Watmough SA, Whitfield CJ, Fenn ME (2014) The importance of atmospheric base cation deposition for preventing soil acidification in the Athabasca Oil Sands Region of Canada. Sci Total Environ 493: $1-11$

Wetzel RG (2001) Limnology, Lake and River Ecosystems ( $3^{\text {rd }}$ ed.). Academic Press, San Diego, USA Winder M, Sommer U (2012) Phytoplankton response to a changing climate. Hydrobiologia 698: 5-16 
Wolfe AP, Baron JS, Cornett RJ (2001) Anthropogenic nitrogen deposition induces rapid ecological changes in alpine lakes of the Colorado Front Range (USA). J Paleolimnol 25: 1-7

Wolfe AP, Perren BB (2001) Chrysophyte microfossils record marked responses to recent environmental changes in high- and mid-arctic lakes. Can J Bot 79: 747-752

Wolfe AP, Siver PA (2013) A hypothesis linking chrysophyte microfossils to lake carbon dynamics on ecological and evolutionary timescales. Glob Planet Change 111: 189-198

Wood S (2016) mgcv: mixed GAM computation vehicle with GCV/AIC/REML smoothness estimation. Available online at: https://cran.r-project.org/web/packages/mgcv/index.html 
Table I Physical and chemical variables of the sixteen study lakes in northwest Saskatchewan.

\begin{tabular}{|c|c|c|c|c|c|c|c|c|c|c|c|c|c|}
\hline Lake & Sampled & $\begin{array}{c}\text { Surface } \\
\text { area (ha) }\end{array}$ & $\begin{array}{l}\text { Coring } \\
\text { Depth } \\
\text { (m) }\end{array}$ & pH & $\begin{array}{c}\text { Alk } \\
(\mathrm{mg} / \mathrm{L})\end{array}$ & $\begin{array}{c}\text { Specific } \\
\text { conductance } \\
(\mu \mathrm{S} / \mathrm{cm})\end{array}$ & $\begin{array}{c}\text { DOC } \\
(\mathrm{mg} / \mathrm{L})\end{array}$ & $\begin{array}{c}\text { Chl- } a \\
(\mathrm{mg} / \mathrm{L})\end{array}$ & $\underset{(\mu \mathrm{g} / \mathrm{L})}{\mathrm{TN}}$ & $\begin{array}{c}\text { TP } \\
(\mu \mathrm{g} / \mathrm{L})\end{array}$ & $\begin{array}{l}\text { DIN: } \\
\text { TP }\end{array}$ & $\begin{array}{c}\text { Mean } \\
\text { DIN:TP }\end{array}$ & $p \mathrm{CO}_{2}$ \\
\hline \multicolumn{14}{|l|}{$N I$} \\
\hline $9 \mathrm{C}$ & 2007 & 155 & 10.5 & 7.10 & 15.0 & 33.0 & 1.8 & 7.3 & 266 & 18.0 & 1.4 & - & 974 \\
\hline $10 Z$ & 2007 & 43 & 10.9 & 7.18 & 16.6 & 34.4 & 3.4 & 5.4 & 380 & 10.0 & 2.7 & - & 969 \\
\hline $10 \mathrm{E}$ & 2007 & 23 & 6.3 & 7.26 & 18.1 & 35.5 & 3.5 & 3.9 & 329 & 12.0 & 2.8 & - & 881 \\
\hline $10 \mathrm{Y}$ & 2007 & 170 & 6.5 & 7.15 & 17.2 & 33.7 & 4.7 & 6.8 & 532 & 12.0 & 3.3 & - & 1053 \\
\hline $\begin{array}{l}6 \mathrm{E} \\
P I\end{array}$ & $2007-2011$ & 18 & 6 & 7.27 & 16.5 & 33.4 & 3.4 & 6.1 & 315 & 16.5 & 3.3 & 2.7 & 942 \\
\hline $10 \mathrm{~A}$ & $2007-2011$ & 38 & 9.5 & 7.11 & 10.0 & 23.6 & 4.6 & 2.6 & 246 & 5.5 & 8.2 & - & 739 \\
\hline $13 \mathrm{~L}$ & 2008-2011 & 88 & 20.3 & 6.97 & 6.6 & 17.2 & 1.6 & 1.5 & 112 & 3.3 & 11.1 & - & 707 \\
\hline $13 \mathrm{~N}$ & 2008-2011 & 150 & 12.2 & 7.13 & 11.6 & 27.2 & 7.1 & 3.1 & 253 & 5.0 & 13.4 & - & 730 \\
\hline $11 \mathrm{G}$ & $2007-2011$ & 41 & 18.1 & 6.98 & 7.7 & 21.4 & 6.5 & 1.3 & 225 & 5.7 & 18.7 & 12.9 & 606 \\
\hline \multicolumn{14}{|l|}{$N R$} \\
\hline $17 \mathrm{~V}$ & $2008-2011$ & 62 & 5.4 & 7.08 & 7.5 & 16.9 & 3.4 & 5.4 & 290 & 14.0 & 2.8 & - & 590 \\
\hline $2 \mathrm{~F}$ & $2007-2011$ & 129 & 7.5 & 6.94 & 7.3 & 17.7 & 4.0 & 4.7 & 279 & 11.8 & 3.0 & - & 695 \\
\hline $2 Q$ & $2008-2011$ & 60 & 9.8 & 6.96 & 6.2 & 13.8 & 4.2 & 4.4 & 361 & 12.0 & 3.3 & - & 693 \\
\hline $17 \mathrm{~J}$ & $2007-2011$ & 9 & 7.4 & 6.93 & 7.0 & 17.0 & 2.7 & 6.2 & 210 & 14.3 & 3.6 & 3.2 & 772 \\
\hline \multicolumn{14}{|l|}{$P R$} \\
\hline $17 \mathrm{P}$ & $2008-2011$ & 63 & 7.4 & 6.77 & 4.2 & 14.1 & 7.1 & 2.0 & 253 & 7.7 & 7.8 & - & 474 \\
\hline $17 \mathrm{~F}$ & $2007-2011$ & 21 & 7.9 & 7.04 & 7.8 & 17.6 & 4.4 & 3.2 & 299 & 6.5 & 7.8 & - & 624 \\
\hline $2 \mathrm{~L}$ & 2008-2011 & 68 & 5.1 & 7.15 & 8.1 & 17.6 & 3.7 & 2.1 & 244 & 7.3 & 12.5 & 9.4 & 544 \\
\hline
\end{tabular}

Lakes are organized by a priori groups identified by the factorial study design. $\mathrm{NI} \mathrm{N}$-limited or $\mathrm{N}$ and $\mathrm{P}$ co-limited impact lakes, $\boldsymbol{P I} \mathrm{P}$-limited impact lakes, $\boldsymbol{N} \boldsymbol{R} \mathrm{N}$-limited or $\mathrm{N}$ and $\mathrm{P}$ co-limited reference lakes $\boldsymbol{P R}$ P-limited reference lakes, $A l k$ alkalinity, $D O C$ dissolved organic carbon, $C h l$ - $a$ chlorophyll a, $T N$ total nitrogen, $T P$ total phosphorus, DIN:TP dissolved inorganic nitrogen to total phosphorus. No water chemistry data were collected from any of the lakes in 2010. Water chemistry was not surveyed in Lake $11 \mathrm{G}$ in 2008. 
Table II Model summary for the factorial generalized additive models (GAMs) for the S-to-D timeseries data, and results from the model selection process. For each smoothing term, EDF effective degrees of freedom, Ref.df reference degrees of freedom, $F$ F-statistic, and $P$-value are shown. The Lake term is treated as a random effect. Model selection shows $D F$ degrees of freedom, BIC Bayesian Information Criteria, $L L$ negative log-likelihood, and deviance explained by each model.

\begin{tabular}{ccccc}
\hline \multicolumn{5}{c}{ Factorial model } \\
\hline Covariate & EDF & Ref.df & $\boldsymbol{F}$ & $\boldsymbol{P}$-value \\
NI & 3.26 & 3.81 & 7.13 & $<0.05$ \\
NR & 1.50 & 1.65 & 8.96 & $<0.05$ \\
PI & 1.49 & 1.65 & 5.29 & $<0.05$ \\
PR & 1.32 & 1.45 & 3.08 & $<0.1$ \\
Lake & 51.94 & 140.00 & 6.61 & $<0.05$ \\
& \multicolumn{5}{c}{ Model selection } \\
\hline \multicolumn{7}{c}{ BIC } & LL & Deviance explained \\
\hline Model & DF & 1328.05 & -465.87 & 86 \\
Factorial & 67.99 & 1304.31 & -471.46 & 85.5 \\
Lake & 62.00 & \multicolumn{5}{c}{}
\end{tabular}


Supplementary Material - Table SI Detailed water chemistry with respect to nitrogen species over multiple sampling years for 16 study lakes in northwest Saskatchewan. DIN dissolved inorganic nitrogen, $T P$ total phosphorus.

\begin{tabular}{|c|c|c|c|c|c|c|}
\hline Lake & $\begin{array}{c}\text { Sample } \\
\text { Year }\end{array}$ & $\begin{array}{c}\text { NH4-N } \\
(\mu \mathrm{mol} / \mathrm{L})\end{array}$ & $\begin{array}{c}\text { NO3-N } \\
(\mu \mathrm{mol} / \mathrm{L})\end{array}$ & $\begin{array}{c}\text { DIN } \\
(\mu \mathrm{mol} / \mathrm{L})\end{array}$ & $\begin{array}{c}\text { TP } \\
(\mu \mathrm{mol} / \mathrm{L})\end{array}$ & DIN:TP \\
\hline \multicolumn{7}{|l|}{$N I$} \\
\hline $9 \mathrm{C}$ & 2007 & 0.714 & 0.071 & 0.786 & 0.581 & 1.35 \\
\hline $10 \mathrm{Z}$ & 2007 & 0.786 & 0.071 & 0.857 & 0.323 & 2.66 \\
\hline $10 \mathrm{E}$ & 2007 & 1.000 & 0.071 & 1.071 & 0.387 & 2.77 \\
\hline $10 \mathrm{Y}$ & 2007 & 1.214 & 0.071 & 1.286 & 0.387 & 3.32 \\
\hline $6 \mathrm{E}$ & 2007 & 1.000 & 0.143 & 1.143 & 0.548 & 2.08 \\
\hline $6 \mathrm{E}$ & 2008 & 0.286 & 0.071 & 0.357 & 0.484 & 0.74 \\
\hline $6 \mathrm{E}$ & 2009 & 2.786 & 0.071 & 2.857 & 0.387 & 7.38 \\
\hline \multicolumn{7}{|l|}{$P I$} \\
\hline \multirow{4}{*}{$10 \mathrm{~A}$} & 2007 & 1.071 & 0.071 & 1.143 & 0.161 & 7.09 \\
\hline & 2008 & 1.857 & 0.357 & 2.214 & 0.258 & 8.58 \\
\hline & 2009 & 0.929 & 0.071 & 1.000 & 0.161 & 6.20 \\
\hline & 2011 & 1.357 & 0.071 & 1.429 & 0.129 & 11.07 \\
\hline \multirow[t]{2}{*}{$13 \mathrm{~L}$} & 2008 & 1.000 & 0.071 & 1.071 & 0.129 & 8.30 \\
\hline & 2009 & 1.000 & 0.071 & 1.071 & 0.065 & 16.61 \\
\hline \multirow[t]{3}{*}{$13 \mathrm{~N}$} & 2008 & 1.857 & 0.571 & 2.429 & 0.194 & 12.55 \\
\hline & 2009 & 1.857 & 0.286 & 2.143 & 0.129 & 16.61 \\
\hline & 2011 & 1.643 & 0.143 & 1.786 & 0.161 & 11.07 \\
\hline \multirow[t]{3}{*}{$11 \mathrm{G}$} & 2008 & 1.357 & 0.786 & 2.143 & 0.097 & 22.14 \\
\hline & 2009 & 3.714 & 0.071 & 3.786 & 0.129 & 29.34 \\
\hline & 2011 & 1.357 & 0.143 & 1.500 & 0.323 & 4.65 \\
\hline \multicolumn{7}{|l|}{$N R$} \\
\hline \multirow[t]{3}{*}{$17 \mathrm{~V}$} & 2008 & 1.286 & 0.071 & 1.357 & 0.452 & 3.01 \\
\hline & 2009 & 0.786 & 0.071 & 0.857 & 0.387 & 2.21 \\
\hline & 2011 & 1.571 & 0.071 & 1.643 & 0.516 & 3.18 \\
\hline \multirow[t]{4}{*}{$2 \mathrm{~F}$} & 2007 & 0.786 & 0.857 & 1.643 & 0.355 & 4.63 \\
\hline & 2008 & 1.214 & 0.071 & 1.286 & 0.419 & 3.07 \\
\hline & 2009 & 1.071 & 0.143 & 1.214 & 0.323 & 3.76 \\
\hline & 2011 & 0.071 & 0.071 & 0.143 & 0.419 & 0.34 \\
\hline \multirow[t]{3}{*}{$2 \mathrm{Q}$} & 2008 & 0.929 & 0.071 & 1.000 & 0.452 & 2.21 \\
\hline & 2009 & 1.071 & 0.071 & 1.143 & 0.258 & 4.43 \\
\hline & 2011 & 1.357 & 0.071 & 1.429 & 0.452 & 3.16 \\
\hline \multirow[t]{4}{*}{$17 \mathrm{~J}$} & 2007 & 1.357 & 0.071 & 1.429 & 0.548 & 2.61 \\
\hline & 2008 & 1.286 & 0.071 & 1.357 & 0.419 & 3.24 \\
\hline & 2009 & 1.214 & 0.143 & 1.357 & 0.419 & 3.24 \\
\hline & 2011 & 1.786 & 0.643 & 2.429 & 0.452 & 5.38 \\
\hline \multicolumn{7}{|l|}{$P R$} \\
\hline \multirow[t]{3}{*}{$17 \mathrm{P}$} & 2008 & 1.571 & 0.143 & 1.714 & 0.194 & 8.86 \\
\hline & 2009 & 2.071 & 0.143 & 2.214 & 0.226 & 9.81 \\
\hline & 2011 & 1.500 & 0.071 & 1.571 & 0.323 & 4.87 \\
\hline \multirow[t]{4}{*}{$17 \mathrm{~F}$} & 2007 & 1.000 & 0.143 & 1.143 & 0.129 & 8.86 \\
\hline & 2008 & 1.286 & 0.071 & 1.357 & 0.194 & 7.01 \\
\hline & 2009 & 1.714 & 0.071 & 1.786 & 0.161 & 11.07 \\
\hline & 2011 & 1.429 & 0.071 & 1.500 & 0.355 & 4.23 \\
\hline \multirow[t]{3}{*}{$2 \mathrm{~L}$} & 2008 & 2.214 & 0.071 & 2.286 & 0.194 & 11.81 \\
\hline & 2009 & 3.071 & 0.071 & 3.143 & 0.161 & 19.49 \\
\hline & 2011 & 2.071 & 0.143 & 2.214 & 0.355 & 6.24 \\
\hline
\end{tabular}


Supplementary Material - Table SII Results from Pearson correlations between the S-to-D index and chrysophyte scale concentrations for each lake. Lakes that do show recent increases in chrysophyte scale concentrations are in bold. Lakes are organized by a priori groups according to the factorial study design.

\begin{tabular}{ccc}
\hline Lake & Pearson's r & $p$ value \\
\hline \multicolumn{3}{c}{ N-limited Impact } \\
$\mathbf{6 E}$ & 0.98 & $<0.005$ \\
$\mathbf{9 C}$ & 0.89 & $<0.005$ \\
$10 \mathrm{Y}$ & 0.95 & $<0.005$ \\
$10 \mathrm{E}$ & 0.49 & $<0.005$ \\
$10 \mathrm{Z}$ & 0.91 & $<0.005$ \\
\multicolumn{4}{c}{ P-limited Impact } \\
$\mathbf{1 0 A}$ & 0.81 & $<0.005$ \\
$\mathbf{1 3 N}$ & 0.91 & $<0.005$ \\
$\mathbf{1 3 L}$ & 0.82 & $<0.005$ \\
$11 \mathrm{G}$ & 0.92 & $<0.005$ \\
\multicolumn{3}{c}{ N-limited Reference } \\
$\mathbf{2 Q}$ & 0.87 & $<0.005$ \\
$2 \mathrm{~F}$ & 0.96 & $<0.005$ \\
$17 \mathrm{~J}$ & 0.95 & $<0.005$ \\
$17 \mathrm{~V}$ & 0.95 & $<0.005$ \\
\multicolumn{3}{c}{ P-limited Reference } \\
$\mathbf{1 7 P}$ & 0.97 & $<0.005$ \\
$\mathbf{1 7 F}$ & 0.78 & $<0.005$ \\
$2 \mathrm{~L}$ & 0.83 & $<0.005$ \\
\hline \multicolumn{3}{c}{}
\end{tabular}




\section{Figure captions}

Fig. 1 Location of the sixteen study lakes in northwest Saskatchewan. The dashed line shows the boundary between the Boreal Shield and Boreal Plains ecozone. Closed circle $=$ N-limited, Open circle $=$ P-limited, Red $=$ Impact lake, Blue $=$ Reference lake

Fig. 2 Non-metric multidimensional scaling (nMDS) of physical and chemical variables for the sixteen study lakes in northwest Saskatchewan. Nutrient limitation status and impact/reference designation according to the factorial study design are also indicated. The dashed line in the centre of the ordination shows the separation between N-limited and P-limited lakes. Imp impact lakes, Ref reference lakes

Fig. 3 Stratigraphies of scaled-chrysophyte relative abundances in eight of the sixteen study lakes in northwest Saskatchewan. Lakes are ordered by the four a priori lake groups identified by the factorial study design. A-B) N-limited or N and P co-limited reference lakes (NI lakes). C-E) P-limited

reference lakes (PI lakes). F) N-limited or N and P co-limited reference lake (NR lake). G-H) P-limited reference lakes $(P R$ lakes)

Fig. 4 Predicted change through time in the S-to-D index under the Lake model. Individual points in each plot show the observed S-to-D index value. Lakes are ordered by lake category: NI N-limited impact lakes $N R$ N-limited reference lakes PI P-limited impact lakes $P R$ P-limited reference lakes. The shaded region in each plot represents the $95 \%$ confidence intervals. Note that the y-scale varies between plots.

Supplementary Material - Fig. S1 Total ${ }^{210} \mathrm{~Pb}$ activities (dashed line), Constant Rate of Supply (CRS) estimated dates and error (filled circles), and age depth models via monotonic cubic spline for all 
sixteen study lakes in northwest Saskatchewan (red line). $r^{2}$ is for total ${ }^{210} \mathrm{~Pb}$ activity fit to a first order exponential decay. Core chronologies are organized by the four a priori lake groups: NI N-limited or N and $\mathrm{P}$ co-limited impact lake, $P I \mathrm{P}$-limited impact lake, $N R \mathrm{~N}$-limited or $\mathrm{N}$ and $\mathrm{P}$ co-limited reference lake, $P R$ P-limited reference lake.

Supplementary Material - Fig. S2 Chrsyophyte scale concentrations and \% carbon in the sediment cores from the sixteen study lakes in northwest Saskatchewan. A) N-limited or N and P co-limited impact lakes B) P-limited impact lakes C) N-limited or N and P co-limited reference lakes D) P-limited reference lakes

Supplementary Material - Fig. S3 GAM smoothers extracted from the Factorial model by group for the S-to-D index time series. Shaded bands represent the upper and lower $95 \%$ confidence intervals for each model. NI N-limited or $\mathrm{N}$ and $\mathrm{P}$ co-limited impact lakes, $P I \mathrm{P}$-limited impact lakes, $N R \mathrm{~N}$-limited or $\mathrm{N}$ and $\mathrm{P}$ co-limited reference lakes, $P R$ P-limited reference lakes. 


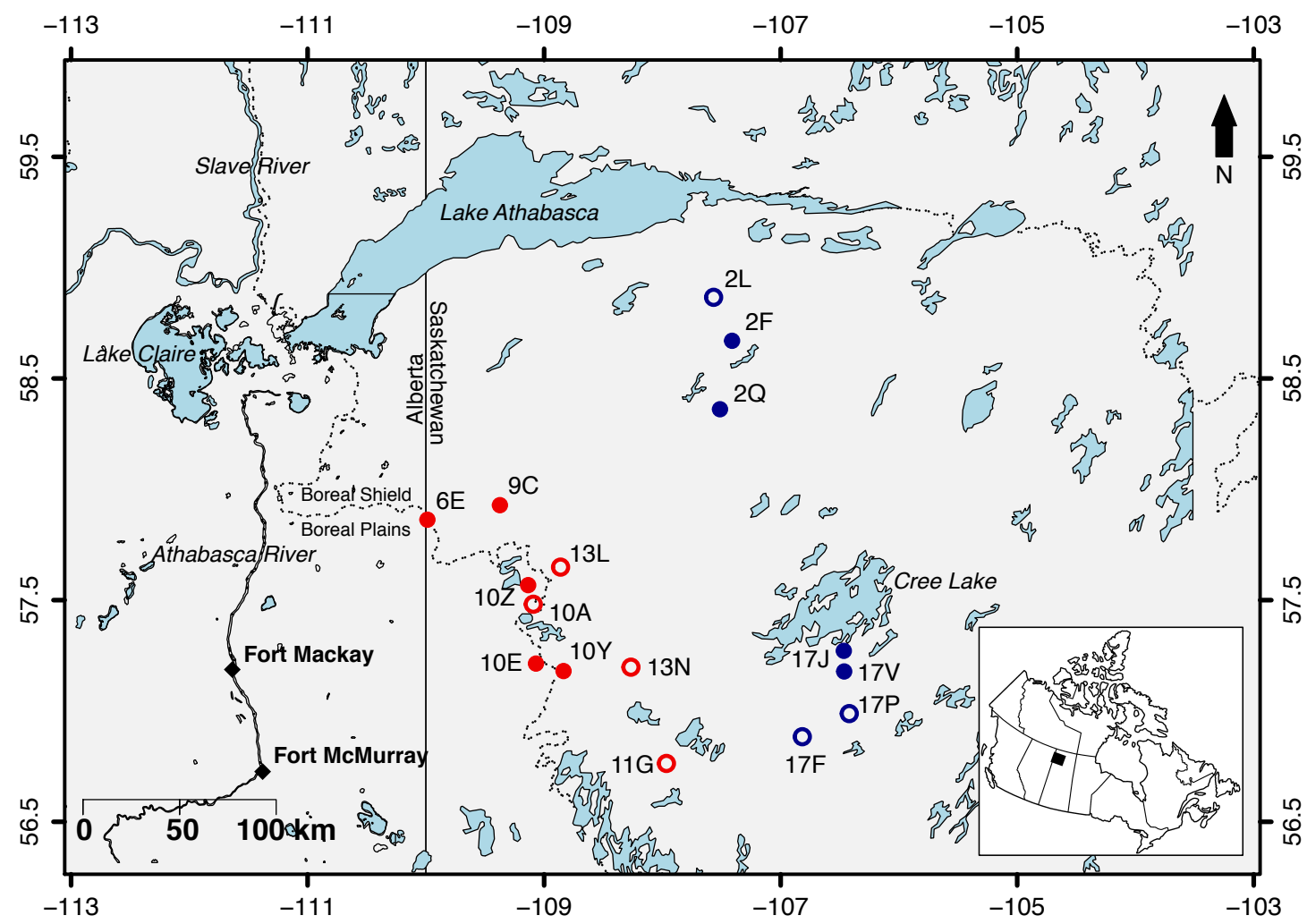

Fig. 1 


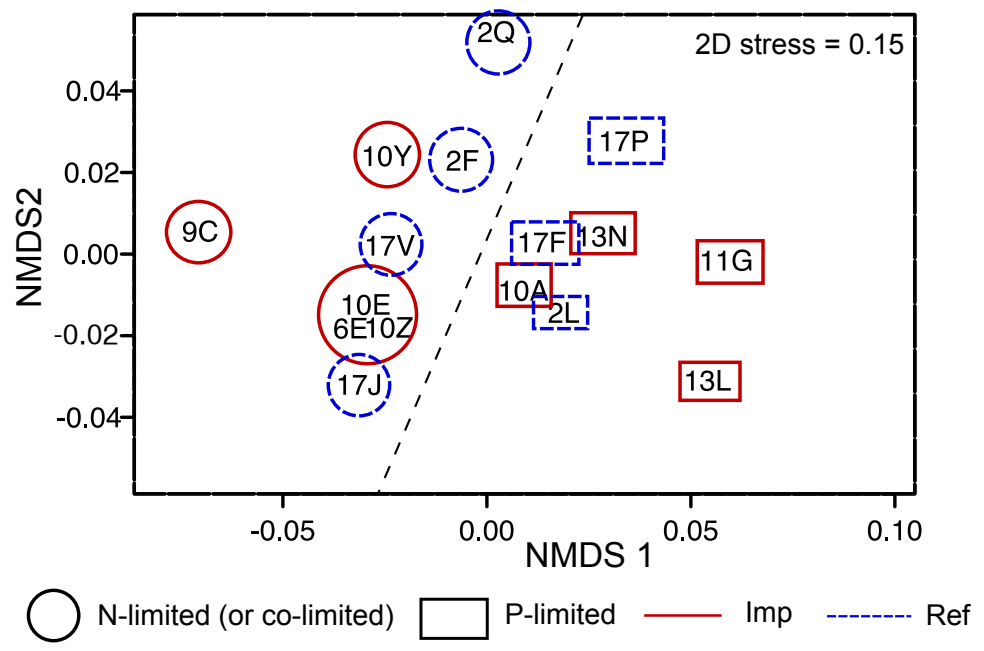

Fig. 2 

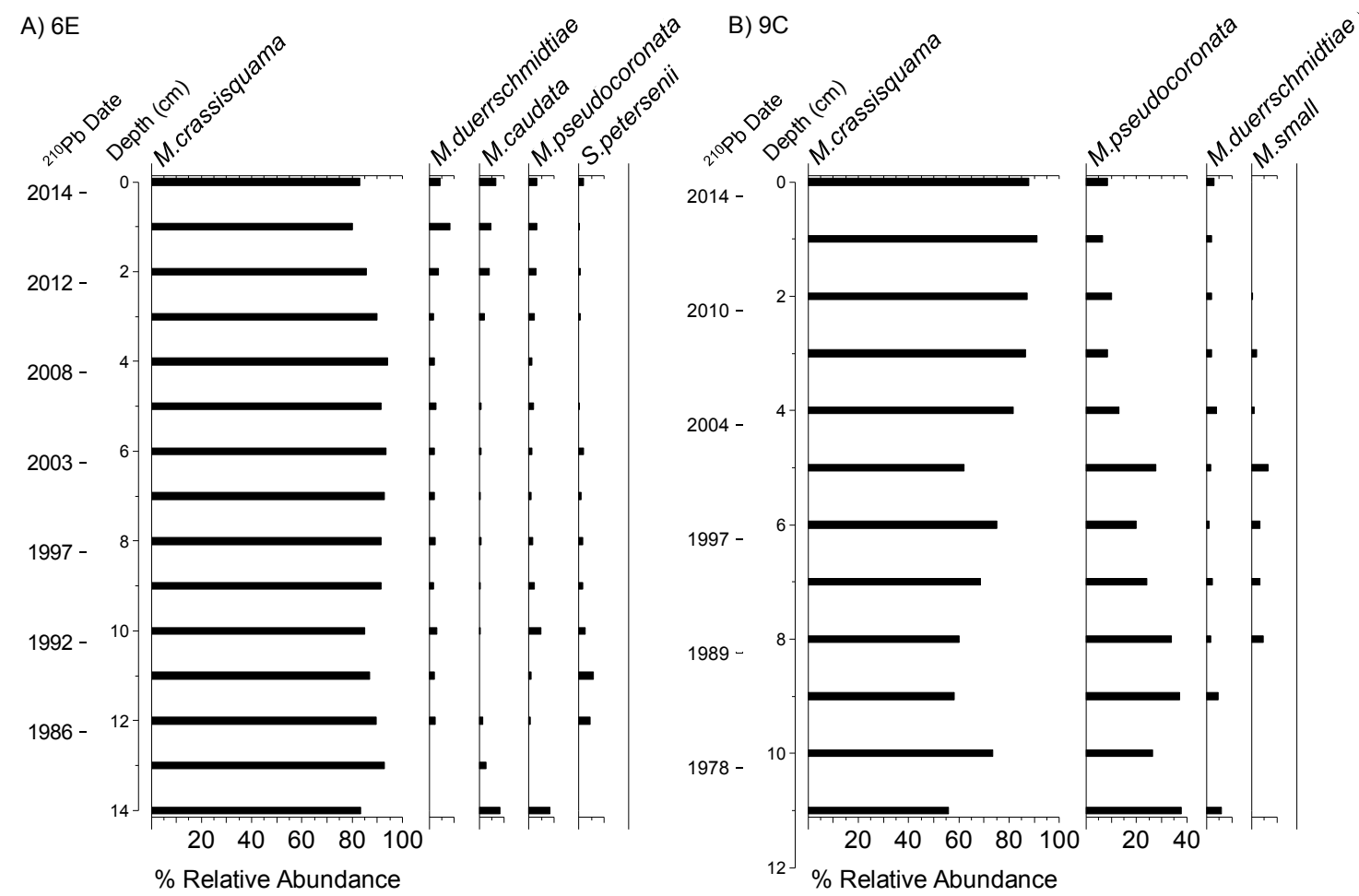

C) $13 \mathrm{~N}$
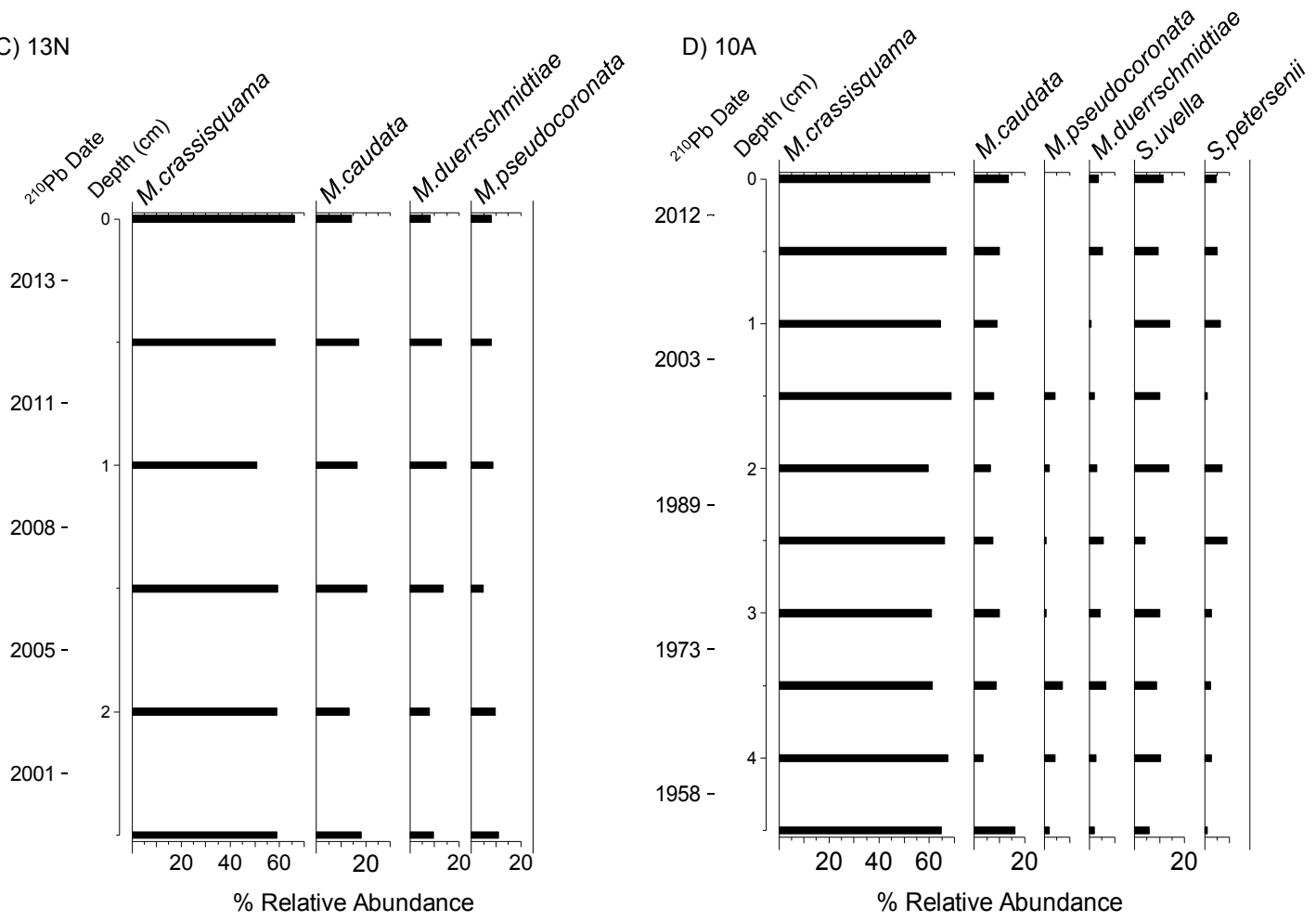

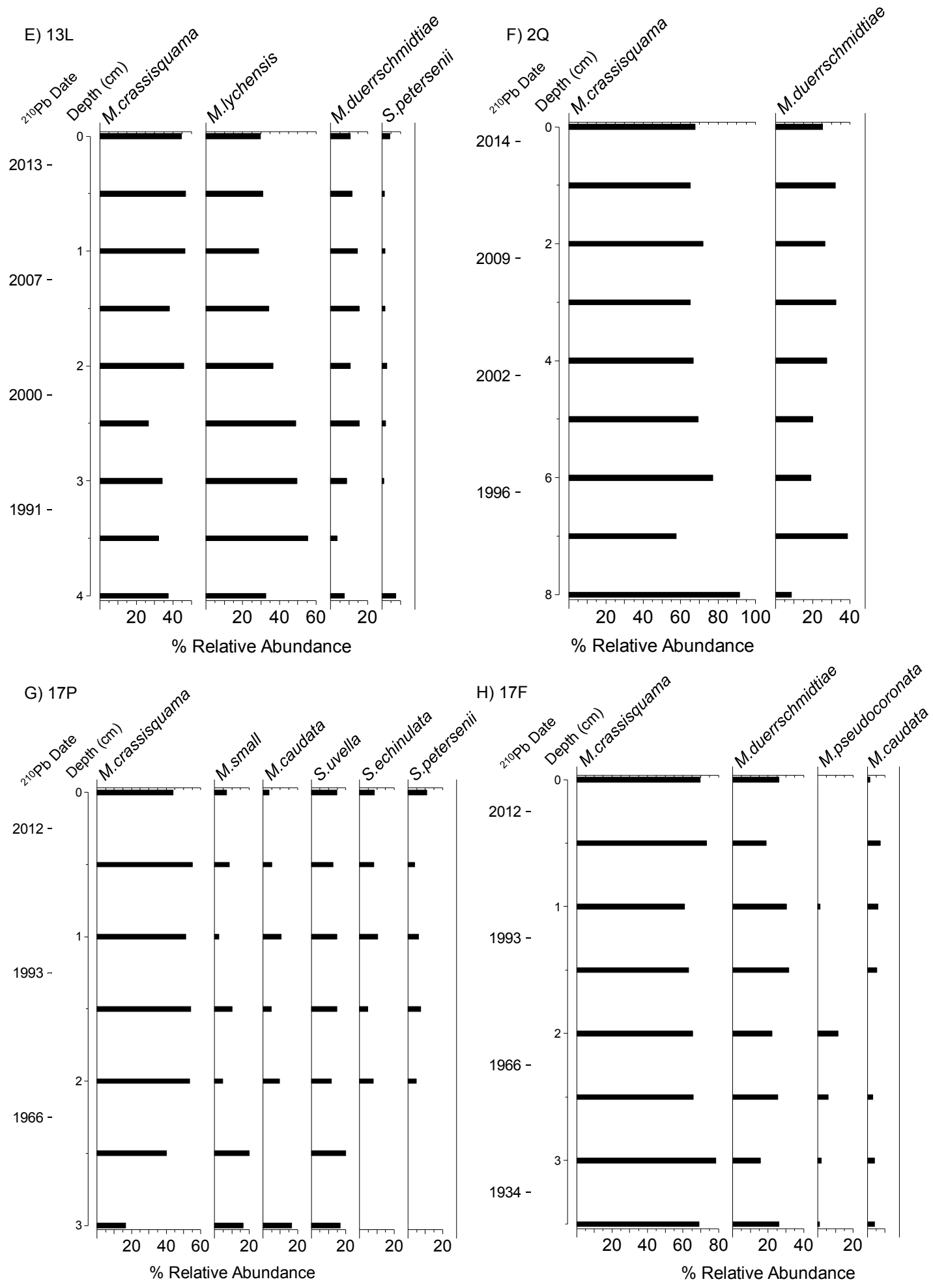

Fig. 3 


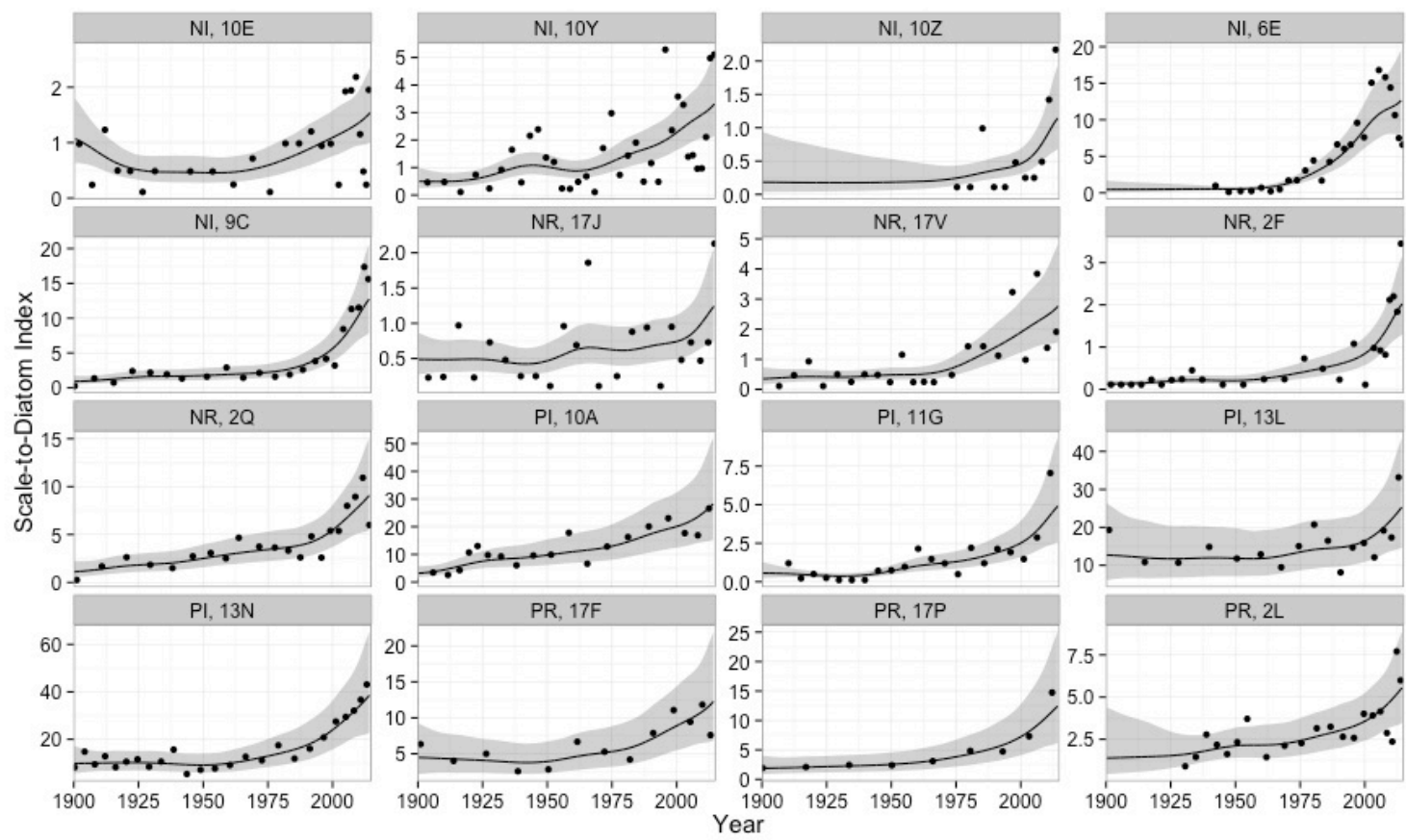

Fig. 4 

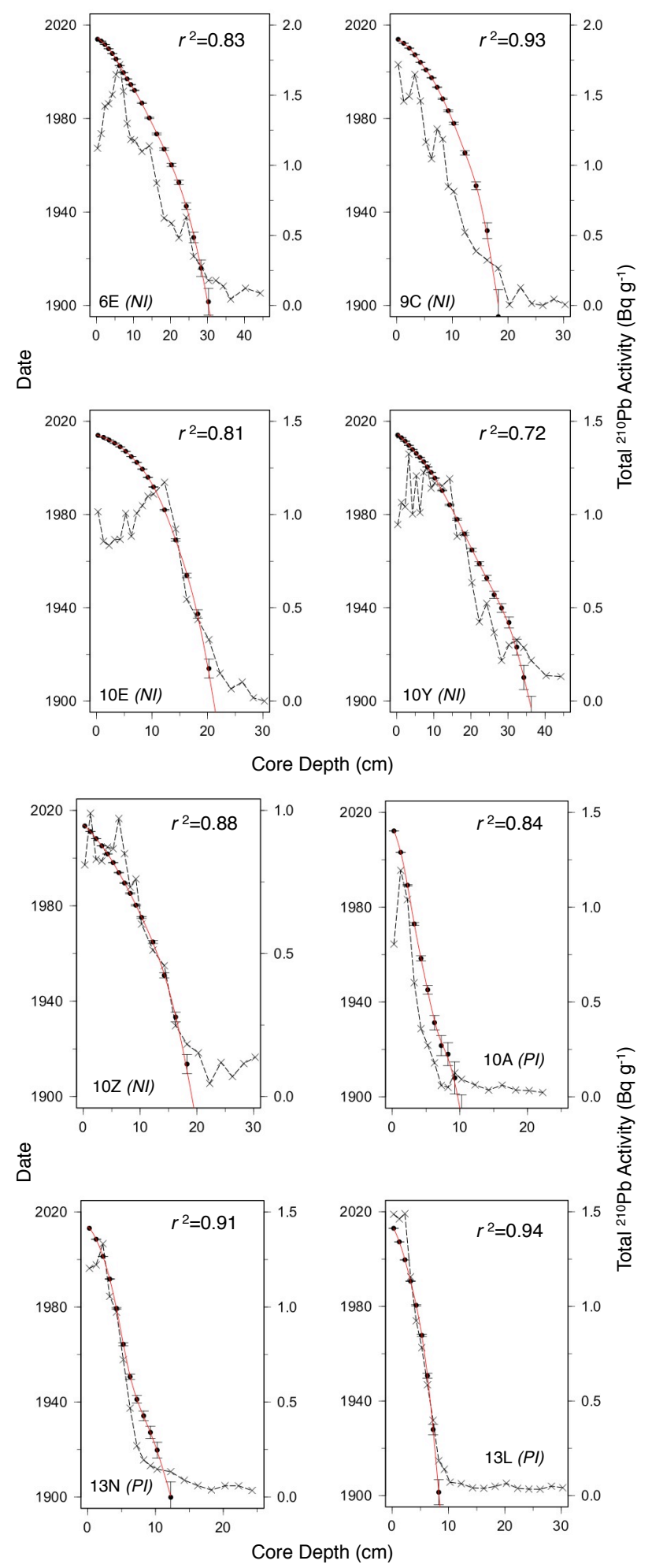

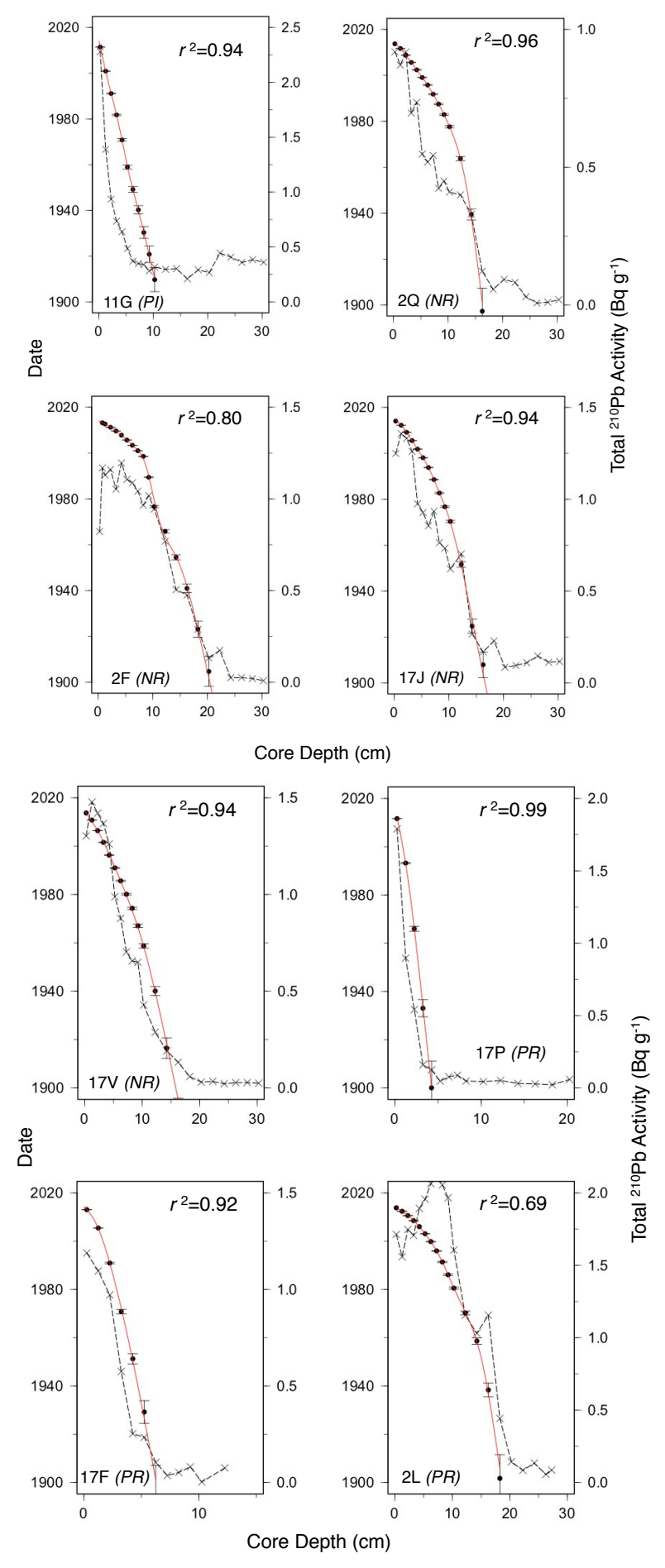

Supplementary Material - Fig. S1 


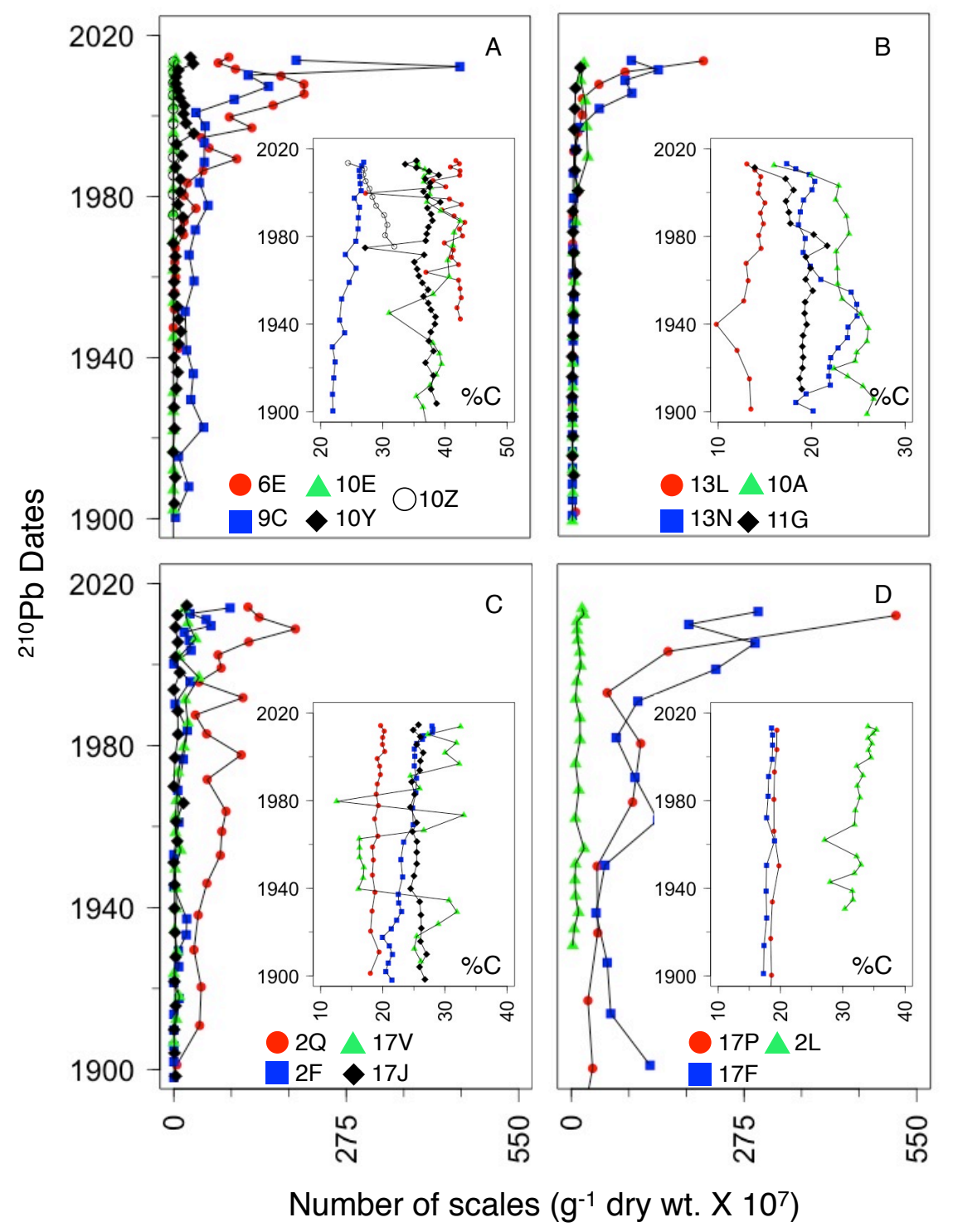

Supplementary Material - Fig. S2 


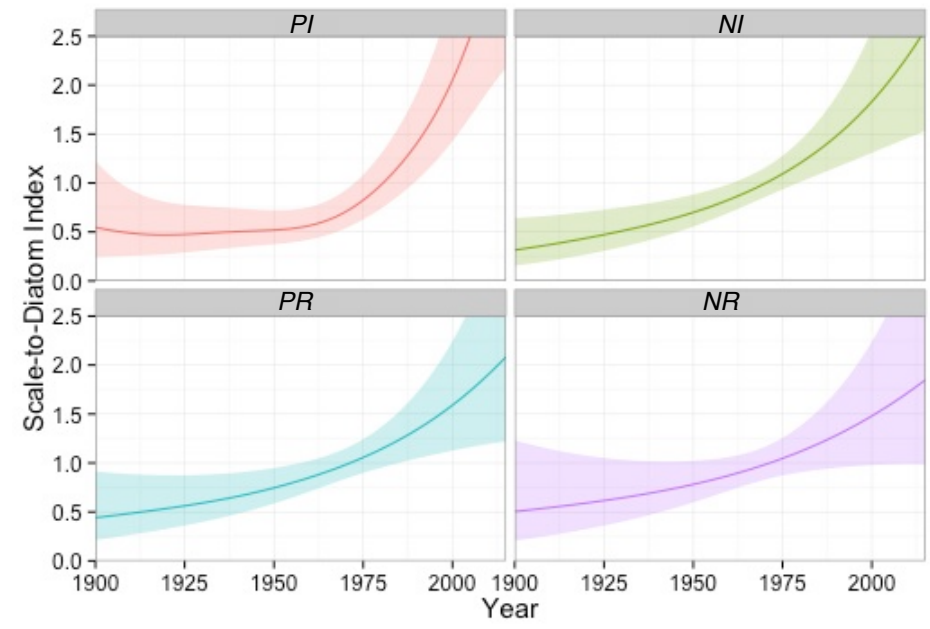

Supplementary Material - Fig. S3 